\title{
Conditioned reinforcing value of the sample stimulus and resistance to change of delayed matching -to -sample performance in pigeons
}

Yusuke Hayashi

West Virginia University

Follow this and additional works at: https://researchrepository.wvu.edu/etd

\section{Recommended Citation}

Hayashi, Yusuke, "Conditioned reinforcing value of the sample stimulus and resistance to change of delayed matching -to -sample performance in pigeons" (2009). Graduate Theses, Dissertations, and Problem Reports. 4476.

https://researchrepository.wvu.edu/etd/4476

This Dissertation is protected by copyright and/or related rights. It has been brought to you by the The Research Repository @ WVU with permission from the rights-holder(s). You are free to use this Dissertation in any way that is permitted by the copyright and related rights legislation that applies to your use. For other uses you must obtain permission from the rights-holder(s) directly, unless additional rights are indicated by a Creative Commons license in the record and/ or on the work itself. This Dissertation has been accepted for inclusion in WVU Graduate Theses, Dissertations, and Problem Reports collection by an authorized administrator of The Research Repository @ WVU.

For more information, please contact researchrepository@mail.wvu.edu. 
Conditioned Reinforcing Value of the Sample Stimulus and Resistance to Change of Delayed Matching-to-Sample Performance in Pigeons

\author{
Yusuke Hayashi \\ Dissertation submitted to the \\ Eberly College of Arts and Sciences \\ at West Virginia University \\ in partial fulfillment of the requirements \\ for the degree of \\ Doctor of Philosophy \\ in \\ Psychology
}

Michael Perone, Ph.D., Chair

Kevin Larkin, Ph.D.

Kennon A. Lattal, Ph.D.

B. Kent Parker, Ph.D.

Oliver Wirth, Ph.D.

Department of Psychology

Morgantown, West Virginia

2009

Keywords: delayed matching-to-sample, resistance to change, behavioral momentum theory, conditioned reinforcement, delay reduction hypothesis, key peck, pigeon 


\begin{abstract}
Conditioned Reinforcing Value of the Sample Stimulus and Resistance to Change of Delayed Matching-to-Sample Performance in Pigeons
\end{abstract}

Yusuke Hayashi

Pigeons were trained on a two-component multiple schedule with a chain schedule in each component. According to a variable-interval schedule in the initial link, pecks on a center key produced a terminal link with a delayed matching-to-sample trial. A trial began with the onset of a red or green (Experiment 1) or green or blue (Experiment 2) light as a sample stimulus on the center key. The sample stimulus was followed by a retention interval during which all keys were dark, and then by comparison stimuli on the side keys. A response to the comparison stimulus that matched the sample stimulus was reinforced by access to food. The multiple-schedule components differed in terms of parameters that theoretically affect the conditioned reinforcing value of the sample stimulus. In Experiment 1, the value of the sample stimulus in one component was altered by increasing the length of the variable-interval schedule in the initial link of the chain schedule. In Experiment 2, the value was altered by superimposing responseindependent food deliveries during the initial link. The conditioned reinforcing value of the sample stimulus was assessed on occasional probes composed of a concurrent-chains schedule. The initial links were equal variable-interval schedules. The terminal links composed of the presentation of the sample stimuli associated with different delays to food reinforcement. To measure resistance to change of delayed matching-to-sample accuracy, stable performance was disrupted by prefeeding and extinction. In both experiments, results showed that there was no systematic relation between the conditioned reinforcing value of the sample stimuli and the resistance to change. Instead, the resistance to change was somewhat greater in the component with the higher rate of primary reinforcement in Experiment 2. This may suggest that, in accord with behavioral momentum theory, the resistance to change of delayed matching-to-sample accuracy is governed by rate of primary reinforcement. 


\section{Acknowledgements}

I would like to thank the members of my dissertation committee, Drs. Mike Perone, Andy Lattal, Oliver Wirth, Kent Parker, and Kevin Larkin, for their helpful and thought-provoking comments regarding this research. I am deeply thankful to my advisor, Mike Perone, for his outstanding mentoring throughout my graduate training. Mike has been immensely supportive of my professional development as an independent researcher. I am very fortunate to have chosen his lab to work in. I would like to thank Chata Dickson, Toshikazu Kuroda, Lindsay Parenti, and Rachael Dietric for assisting me in running daily sessions. I also would like to thank Jeff Everly and Jessica Long for their help in conducting experiments in the Perone Lab. Finally, I would like to thank my family for their assistance throughout my graduate career. I especially would like to thank Makiko Okamoto for her continuous support and encouragement. 
Table of Contents

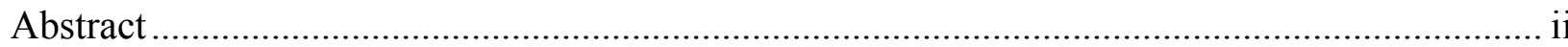

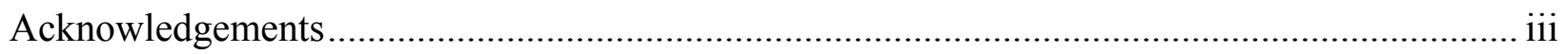

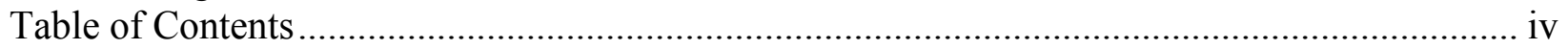

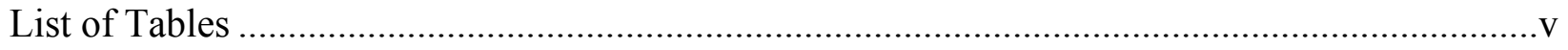

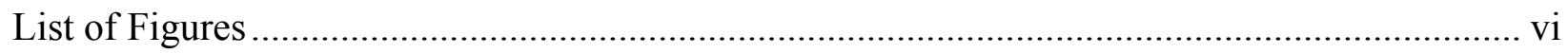

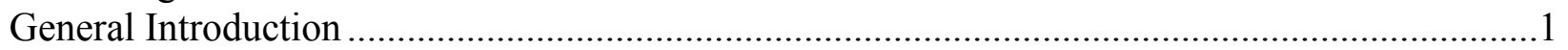

Resistance to Change of the Discriminated Operant .....................................................4

Resistance to Change of Discrimination........................................................................6

Delay Reduction and Resistance to Change of DMTS Accuracy .....................................10

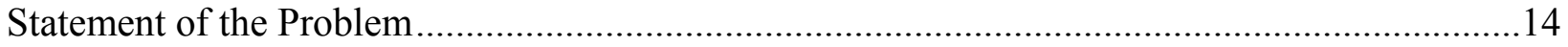

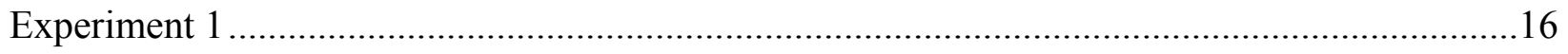

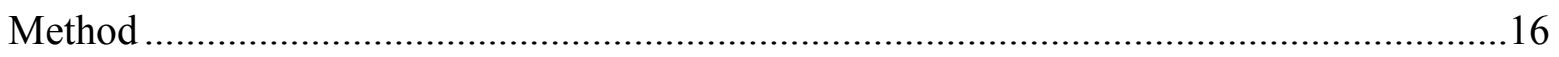

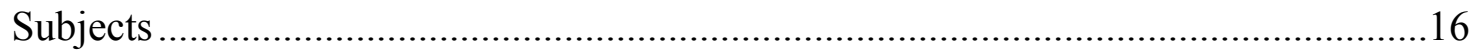

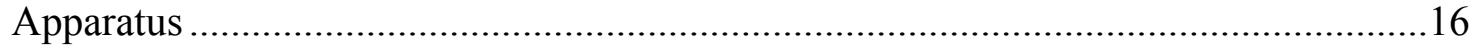

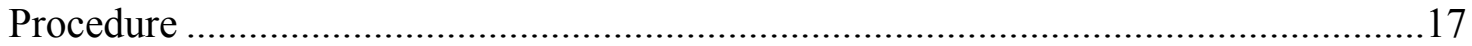

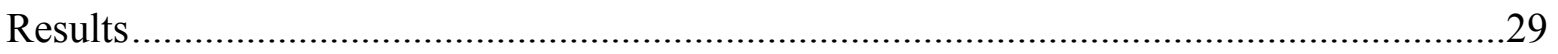

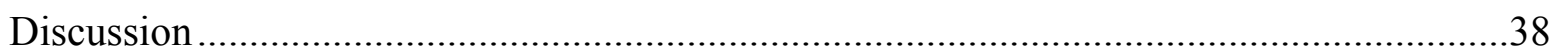

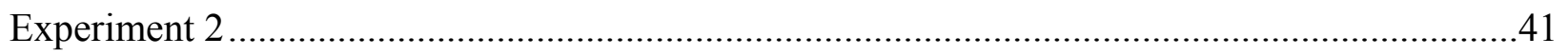

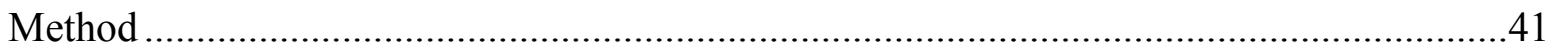

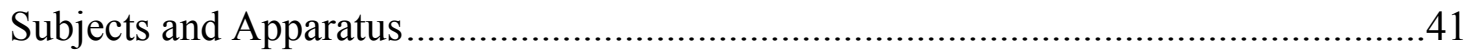

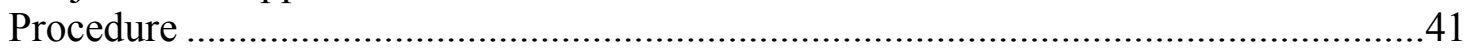

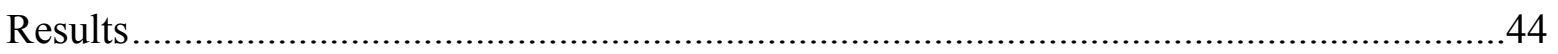

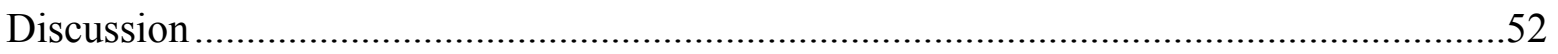

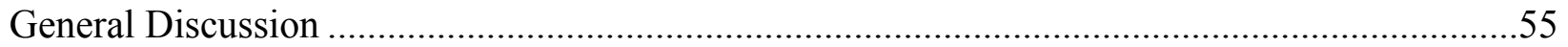

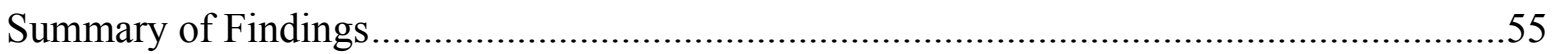

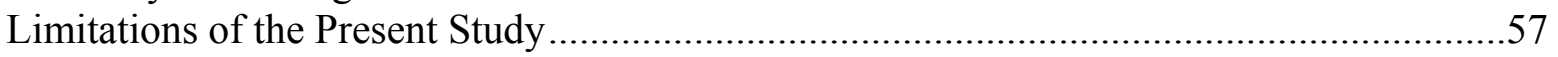

Extension of Resistance to Change Literature .............................................................59

Value of a Conditioned Reinforcer and Baseline DMTS Performance .............................62

Value of a Conditioned Reinforcer and Behavioral Contrast .....................................65

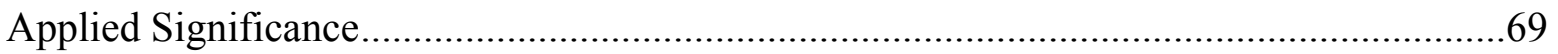

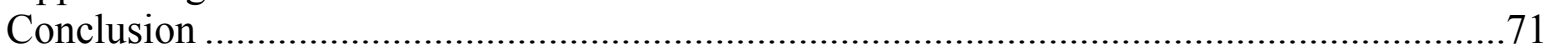

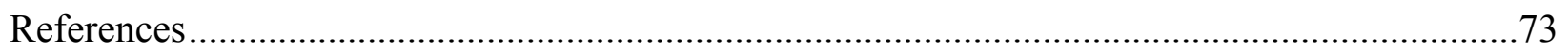




\section{List of Tables}

Table 1. Final procedural parameters of the DMTS trial and the probe for each pigeon in Experiments 1 and 2

Table 2. Initial-link VI schedules, number of sessions, and tests of resistance to change for each pigeon in Experiment 1 ..... .26

Table 3. Amount of food consumed (g) during prefeeding sessions in Experiments 1 and 2 ......27

Table 4. The VT-food schedule superimposed on the initial-link VI schedule, number of sessions, and tests of resistance to change for each pigeon in Experiment 2 


\section{List of Figures}

Figure 1. Mean rates of responses per minute as a function of the initial-link VI length in Experiment 1

Figure 2. Mean $\log d$ (left panel) and $\log d$ expressed as a proportion of the first condition with the same VI schedules in both components (right panel) as a function of the initial-link VI length in Experiment 1

Figure 3. Mean choice proportion for sample stimuli correlated with greater reduction in delay to reinforcement during the probes as a function of each experimental condition in Experiment 1

Figure 4. Response rates during the VI initial links expressed as a log proportion of the mean of the last five baseline sessions immediately prior to each resistance to change test as a function of successive test sessions in Experiment 1.

Figure 5. Log $d$ expressed as a log proportion of the mean of the last five baseline sessions immediately prior to each resistance to change test as a function of a moving window of three blocks of eight DMTS trials in Experiment 1

Figure 6. Mean rates of responses per minute as a function of the duration of the VT-food schedule superimposed on the initial-link VI schedules in Experiment 2.

Figure 7. Mean $\log d$ (left panel) and $\log d$ expressed as a proportion of the first condition with no VT-food schedule superimposed in both components (right panel) as a function of the duration of the VT-food schedule superimposed in Experiment 2.

Figure 8. Mean choice proportion for sample stimuli correlated with greater reduction in delay to reinforcement during probes as a function of each experimental condition in Experiment 2 .......47

Figure 9. Response rates during the VI initial links expressed as a log proportion of the mean of the last five baseline sessions immediately prior to each resistance to change test as a function of successive test sessions in Experiment 2 .....

Figure 10. Log $d$ expressed as a log proportion of the mean of the last five baseline sessions immediately prior to each resistance to change test as a function of a moving window of three blocks of eight DMTS trials in Experiment 2. 


\section{General Introduction}

In an effort to contrast his operant paradigm to Pavlov's respondent paradigm, Skinner (1938/1966) emphasized the control of behavior by stimuli that follow the behavior (Dinsmoor, 1995). Despite Skinner's emphasis, the analysis of control by stimuli that precede behavior plays a critical role in achieving the behaviorist's goals of prediction and control. As noted by Rilling (1977), “[a] reinforcer never occurs in a vacuum, isolated from outside influences” (p. 432). As Dinsmoor also put it, virtually all behavior is "under the exquisitely detailed control of surrounding stimuli, some impinging from outside the organism, others arising from within its boundaries" (p. 52).

Stimulus control, a term used in both operant and respondent paradigms, refers to "the extent to which the value of an antecedent stimulus determines the probability of occurrence of a conditioned response" (Terrace, 1966, p. 271). In the operant paradigm, the smallest units of stimulus control are the simple discrimination and the conditional discrimination (Saunders \& Williams, 1998). Simple discrimination involves a three-term contingency, which consists of a stimulus preceding a response (antecedent stimulus), the response, and the stimulus that follows the response (consequence). In a typical simple discrimination procedure, for example, a reinforcer occasionally follows the response in the presence of one stimulus (the positive stimulus, or "S+") but not in the presence of another stimulus (the negative stimulus, or "S-").

Conditional discrimination involves a four-term contingency (Sidman, 1986) in which a simple discrimination is under the control of another stimulus. A matching-to-sample (MTS) procedure is commonly used to study conditional discrimination. In a prototypical MTS procedure with pigeons (e.g., Cumming \& Berryman, 1965), a trial begins with the presentation of a sample stimulus (e.g., a red or green light) on the center response key of a three-key 
chamber. A pigeon's peck on the center key produces two comparison stimuli on the side keys. One is the same color as the sample stimulus and the other is different. In a simultaneous MTS procedure, the sample stimulus remains on the center key. In a delayed matching-to-sample (DMTS) procedure, a peck on the center key turns off the sample stimulus and starts a retention interval during which all keys are dark. After the retention interval, two comparison stimuli are presented. In both procedures, a single peck on the comparison stimulus that matches the sample stimulus is followed by a food reinforcer, whereas a response to the non-matching comparison stimulus is followed by a blackout during which all lights in the chamber are turned off. Trials are separated by an intertrial interval (ITI) during which all lights are off. An MTS procedure involves conditional discrimination in that the function of the comparison stimuli depends upon the sample stimulus presented on each trial: the sample stimulus determines which comparison stimulus is associated with reinforcement. The most commonly used dependent measure in an MTS procedure is accuracy, represented by the proportion of trials in which a matching response is made.

The history of the study of stimulus control in the operant paradigm reveals that it originated in comparative psychology (e.g., Yerkes \& Petrunkevitch, 1925) under Darwin’s (1872/1955) influence (Harrison, 1991). Since then, simple discrimination and conditional discrimination have been studied extensively in experimental and applied contexts with both human and nonhuman subjects.

According to Harrison (1991), the study of stimulus control centers around the following problem areas: acquisition of discrimination (e.g., errorless learning, Terrace, 1963), the effects of discrimination training on responding to novel stimuli (e.g., stimulus generalization, Guttman \& Kalish, 1956), and stimulus control as a natural phenomenon (e.g., categorization, Herrnstein, 
1979). For each problem area, a wide variety of variables have been identified that affect discrimination (see Carter \& Werner, 1978, Harrison, Mackay, 1991, \& for review).

Compared with acquisition or maintenance of discrimination, however, relatively less empirical attention has been paid to persistence of discrimination. Historically, the persistence of discrimination was identified, for example, with the conditioned tendency to evoke an associated reaction (Hull, 1943), which was a fundamental unit of learning in the associative stimulusresponse (S-R) tradition (Williams, 1984). More recently, however, the persistence of discrimination has been identified with the disruption of stable performance by altering environmental conditions. In other words, the persistence refers to the strength of discrimination and can be measured by resistance to such environmental disruptions as satiation or extinction (cf. Nevin, Milo, Odum, \& Shahan, 2003).

The present study was designed to investigate the resistance of conditional discrimination to disruption. Throughout the study, pigeons completed a DMTS task embedded in a multiple schedule. The components differed in terms of parameters that theoretically affect the conditioned reinforcing value of the sample stimulus as determined by reduction in delay to reinforcement correlated with the onset of the sample stimulus. In the first experiment, the value of the sample stimulus in one component was altered by increasing the average interval between food reinforcers. In the second experiment, the value was altered by decreasing the interval. Resistance to change was assessed by introducing environmental disruptors. The primary purpose of the present study was to investigate the role played by the conditioned reinforcing value of the sample stimuli on resistance to change of conditional discrimination.

Before resistance to change of conditional discrimination will be further discussed, however, resistance to change in general will be discussed. 


\section{Resistance to Change of the Discriminated Operant}

Resistance to change is a measure of persistence of behavior when disruptive events are introduced. It is theoretically tied to the construct of response strength (e.g., Nevin, 1974). The majority of studies on resistance to change have employed a multiple schedule. In a multiple schedule, two or more independent schedules of reinforcement alternate and each schedule is signaled by a stimulus. This stimulus-schedule combination defines not only a schedule component but also a discriminated operant. A discriminated operant consists of a stimulus preceding behavior, the behavior, and the behavior's consequence (Skinner, 1969). As studied in a multiple schedule, therefore, resistance to change is a property of a discriminated operant (e.g., Nevin \& Grace, 2000).

In a representative study on resistance to change (e.g., Nevin, 1974, Experiment 1), fooddeprived pigeons were trained on a multiple schedule in which independent variable-interval (VI) 60-s and VI 180-s schedules alternated regularly. The VI 60-s and VI 180-s components were correlated with red and green keys, respectively. The components lasted for $60 \mathrm{~s}$ and were separated by a 30-s intercomponent interval (ICI). After response rates in each component stabilized (baseline), responding was disrupted by providing food during the ICI (disruption probe). Resistance to change was assessed by expressing the rate of responding during the disruption probe as a proportion of the rate during the preceding baseline. The smaller the proportional change, the greater the resistance to change. Nevin found that resistance to change was greater in the component with the higher reinforcement rate: the VI 60-s component. Nevin (Experiment 3) also found that when components differed in the amount of the food reinforcer, rather than the rate of reinforcement, resistance to change was greater in the component with larger amount. 
Since Nevin's (1974) seminal work, a great number of studies have been conducted using similar procedures. Commonly used disruptors in these studies include (a) providing food independently of responding during ICIs (hereafter ICI food), (b) feeding subjects prior to experimental sessions (hereafter prefeeding), and (c) extinction, in which delivery of reinforcers is discontinued. Whereas ICI food and prefeeding leave the contingencies within the multipleschedule components unchanged, extinction involves a change. The former procedures are designated as external disruptors and the latter as an internal disruptor (cf. Harper \& McLean, 1992). Although the effects of ICI food and prefeeding as external disruptors are often similar to those of extinction as an internal disruptor, several studies have found that effects of external and internal disruptors differ (e.g., Harper \& McLean; Nevin, 1984). Cohen, Riley, and Weigle (1993), for example, found that when response-independent food was delivered during (rather than between) multiple-schedule components as an internal disruptor, there was no systematic relation between the resistance to change and the baseline rates of reinforcement.

As in the case of internal disruptors, for example, there are some failures to replicate the general finding that resistance to change is greater in the component with higher rate or amount of reinforcement. A wide variety of studies using different procedures and subjects, however, have obtained the general finding and its reliability and generality have been well established (see Nevin, 1979, 1992; Nevin \& Grace, 2000, for review). This led to the development of behavioral momentum theory (Nevin, 1992). According to behavioral momentum theory, response rate and resistance to change are separate aspects of the discriminated operant as defined by the three-term contingency. Whereas response rate is determined by the responsereinforcer operant contingency, resistance to change is determined by the stimulus-reinforcer Pavlovian contingency. 
The Pavlovian relation between a stimulus context and reinforcers is a direct function of rate of reinforcement in that stimulus context. Whether reinforcers are dependent on, or independent of, responding, resistance to change is enhanced by all reinforcers obtained in a particular stimulus context. This was empirically demonstrated, for example, by Nevin, Tota, Torquato, and Shull (1990, Experiment 1). They trained pigeons in a two-component multiple schedule with equal VI 60-s schedules. In one component, they added a variable-time (VT) food schedule according to which food was delivered independently of responding after variable intervals of time. While rate of responding during baseline was lower in the component with the added response-independent food, resistance to prefeeding and extinction was greater in that component. This finding suggests that whereas the response-independent food degrades the operant response-reinforcer contingency that governs baseline rate of responding, it enhances the Pavlovian stimulus-reinforcer contingency that governs resistance to change.

\section{Resistance to Change of Discrimination}

The aforementioned studies on resistance to change of rate of responding in a multiple schedule involve stimulus control in that resistance to change is a property of the discriminated operant. It is important to note, however, that these studies do not investigate the resistance to change of discrimination per se. As a distinct area of research, resistance to change of discrimination would be worthwhile for at least two reasons.

First, from a theoretical perspective, research on resistance to change of discrimination can test the generality of behavioral momentum theory. As Nevin et al. (2003) noted:

If the strengthening effect of reinforcement is identified with resistance to change ... the quality of performance--that is, the extent to which it conforms to the different 
contingencies signaled by different stimuli--may be strengthened by reinforcement in the same way as sheer quantity of performance as measured by response rate. (p. 307) That is, the studies on resistance to change of discrimination would tell us whether or not the scope of behavioral momentum theory can be expanded from free-operant responding to discrimination performance. In addition, further understanding of resistance to change (or strength) of discrimination could lead to better understanding of the mechanisms involved in discrimination--a critical component in the three-term contingency as a fundamental analytic unit in the science of behavior (Skinner, 1969).

Second, from a practical perspective, research on resistance to change of discrimination could contribute to the development of instructional programs for difficult-to-teach populations such as people with mental retardation (Dube \& Mcllvane, 2002). In general, the knowledge derived from research on resistance to change of discrimination could help practitioners to make desired stimulus control more persistent as well as to make undesired stimulus control less persistent. In particular, as McIlvane and Dube (2000) noted, it could lead to better technology to facilitate transfer of stimulus control. Consider, for example, the situation in which a discriminative stimulus does not evoke target behavior. If this is solved by using a prompt procedure in which a supplemental cue is provided that evokes the target behavior, it is of practical significance to reduce the frequency of presenting the supplemental cue, while at the same time to establish the control of the target behavior by the discriminative stimulus alone (i.e., the phenomenon described as transfer of stimulus control from the cue to the discriminative stimulus). To achieve this transfer of stimulus control, the knowledge from studies on resistance to change of discrimination is useful. It informs us that the strength of the control by the 
supplemental cue needs to be decreased while the strength of the control of the discriminative stimulus needs to be increased.

In spite of this theoretical and practical significance, however, resistance to change of discrimination has not received much empirical attention. There are some notable exceptions, however, which investigated resistance to change of DMTS accuracy.

Nevin and Grosch (1990) first investigated resistance to change of DMTS accuracy. They trained pigeons in a DMTS procedure with red and green lights. The sample stimulus (red or green) remained on the center key for $5 \mathrm{~s}$, which was followed by a retention interval during which all lights were turned off. Immediately after the retention interval, comparison stimuli (red and green) were presented on the side keys. The duration of the food reinforcer (1.5 or 4.5-s access to food) for a correct match was signaled with auditory stimuli throughout a trial. Stable DMTS accuracy was disrupted by injections of sodium pentobarbital, onset of the houselight during the retention interval, and reduced sample duration. Resistance to change of DMTS accuracy was not systematically affected by the duration of food reinforcer. This is contrary to what would be expected from the studies of resistance to change of rate of responding in which multiple-schedule components differed in the duration of reinforcer (e.g., Nevin, 1974, Experiment 3). However, the use of the unconventional disruptors described above makes it difficult to come to any conclusive statement.

Schaal, Odum, and Shahan (2000, Experiment 2) also examined resistance to change of DMTS accuracy. Pigeons were trained on a two-component multiple schedule. Each component was composed of chain schedules consisting of a VI schedule and a DMTS trial (hereafter multiple chain VI-DMTS chain VI-DMTS schedule). In each chain, pecks on the center key produced a DMTS trial according to a VI 20-s in one component and a VI 120-s in the other 
component. The DMTS trials were the same in both components. After DMTS accuracy stabilized at a retention interval of $0.1 \mathrm{~s}$, the duration of the retention interval was successively increased to $27 \mathrm{~s}$ across several phases. DMTS accuracy was more resistant to the disruptive effects of increasing the retention interval (as an internal disruptor) in the component with the VI 120-s schedule leading to the DMTS trial than in the component with the VI 20-s schedule.

By adopting the multiple chain VI-DMTS chain VI-DMTS procedure developed by Schaal et al. (2000), Nevin et al. (2003) also investigated resistance to change of DMTS accuracy in pigeons. While identical VI 30-s schedules were arranged in both components, the components differed in the probability of reinforcement for correct matches. In one component, correct matches were reinforced with probability of .8 (i.e., approximately 4 out of 5 correct matches were reinforced). In the other component, the reinforcement probability was .2 (1 out of 5). Stable DMTS accuracy was disrupted by prefeeding, ICI food, extinction, and an increased retention interval. DMTS accuracy was more resistant to change in the component with the higher probability of reinforcement. Odum, Shahan, and Nevin (2005) replicated this study using a DMTS procedure with retention intervals ranging from $0.1 \mathrm{~s}$ to $8 \mathrm{~s}$ and obtained similar results.

Finally, also using the multiple chain VI-DMTS chain VI-DMTS procedure, Nevin, Ward, Jimenez-Gomez, Odum, and Shahan (2009) investigated the relation between the differential outcome effect and resistance to change of DMTS accuracy. In one component (the sameoutcome component), the probability of reinforcement was the same for both sample-comparison relations (e.g., .9). In the other component (the different-outcomes component), on the other hand, the probability of reinforcement was .9 for one sample-comparison relation and .1 for the other. Stable DMTS accuracy was disrupted by prefeeding, ICI food, extinction, and flashing lights. The baseline DMTS accuracy was overall higher in the different-outcomes component 
than in the same-outcome component. However, DMTS accuracy was more resistant to change in the same-outcome component than in the different-outcomes component. They concluded that arranging differential outcomes affects baseline DMTS accuracy but not resistance to change.

\section{Delay Reduction and Resistance to Change of DMTS Accuracy}

According to behavioral momentum theory, resistance to change is determined by the stimulus-reinforcer relation which in turn is a direct function of rate of reinforcement in the stimulus context. The results of the studies by Nevin and his colleagues (Nevin et al., 2003, 2009; Odum et al., 2005) are in accord with the theory in that resistance to change of DMTS accuracy was greater in the component with the higher rate of reinforcement (e.g., the component with reinforcement probability of .8 for correct matches rather than .2 ). The results of Schaal et al.'s (2000) study, however, are contradictory to the theory in that resistance to change was greater in the component with lower rate of reinforcement (the component with the VI 120-s schedule leading to the DMTS trial rather than the VI 20-s).

Nevin et al. (2003) pointed out three factors that could account for the difference between the results of their study and those of Schaal et al. (2000). First, while Schaal et al. examined steady-state DMTS accuracy (at least 20 sessions at each retention interval), Nevin et al. examined the DMTS accuracy in transition (shortly after a disruptor was introduced). Second, Schaal et al. disrupted DMTS accuracy by increasing the delay between the sample offset and the comparison onset, which is an internal disruptor. As mentioned earlier, research has shown that effects of internal disruptors could be different from effects of external disruptors such as prefeeding. Finally, in Schaal et al.'s study, the reinforcing value of the DMTS trials was greater in the component with the VI 120-s schedule because the sample stimulus in the component was 
correlated with greater reduction in delay to reinforcement (cf. delay-reduction hypothesis: Fantino, 1977).

It is possible that either the different measures of assessing resistance to change (accuracy in steady state or in transition) or the different types of disruptors (internal or external disruptors) played a critical role in generating the difference between the two studies. Indeed, Nevin et al. (2003) considered the types of disruptors as a critical variable in generating the difference (p. 318). However, an analysis emphasizing the conditioned reinforcing value of the sample stimuli has the potential to reconcile the apparently discrepant data from Nevin et al. and Schaal et al. (2000). As Sidman (1960/1988) noted, "It is the job of science to find orderly relations among phenomena, not differences" (p. 15). Science advances "by integrating, and not by throwing out, seemingly discrepant data" (p. 83). Along with Sidman' claim, effects of the conditioned reinforcing value of the sample stimuli on resistance to change of discrimination were further investigated in this study.

In a DMTS procedure, the sample stimulus may have both discriminative and conditioned reinforcing functions (cf. Keller \& Schoenfeld, 1950). Wixted (1989) argued that a DMTS arrangement is procedurally similar to a conditioned reinforcement arrangement in that the onset of the sample stimulus reliably signals the availability of food reinforcement. Based on the delay-reduction hypothesis (e.g., Fantino, 1977), Wixted further argued that DMTS accuracy is a function of the conditioned reinforcing value of the sample stimulus as determined by the average reduction in delay to reinforcement correlated with the onset of the sample stimuli (see Hartl, Dougherty, \& Wixted, 1996, for the empirical support. See also Roberts \& Kraemer, 1982; Santi, 1984, for a similar analysis based on Gibbon's (1977) scalar expectancy theory). According to the delay-reduction hypothesis, the effectiveness of a stimulus as a conditioned 
reinforcer is determined by the immediacy of a primary (food) reinforcer following the onset of the stimulus relative to the average time between food reinforcers. Based on the hypothesis, the conditioned reinforcing value of the sample stimulus $(v)$ is calculated in this manner (cf. Hartl \& Fantino, 1996):

$$
v=f\left(\frac{T-t_{s}}{T}\right)
$$

where $T$ refers to average interreinforcement interval, and $t_{s}$ refers to average time to reinforcement following the onset of the sample stimulus--a period that includes the duration of the sample-stimulus presentation and the retention interval.

According to Equation 1, if average interreinforcement interval $(T)$ is held constant, the conditioned reinforcing value of the sample stimulus $(v)$ is an inverse function of average time to reinforcement following the onset of the sample stimulus $\left(t_{s}\right)$. Therefore, procedures that should decrease the post-sample delay to reinforcement (e.g., by increasing probability of reinforcement) should enhance the conditioned reinforcing value of the sample stimulus. Also, Equation 1 indicates that if average time to reinforcement following the onset of the sample stimulus $\left(t_{s}\right)$ is held constant, the conditioned reinforcing value of the sample stimulus $(v)$ is a direct function of average interreinforcement interval $(T)$. Therefore, procedures that increase interreinforcement interval (e.g., by increasing the ITI duration) should also enhance the conditioned reinforcing value of the sample stimulus.

If the delay-reduction analysis of DMTS accuracy is applied to resistance to change, the results of both Nevin et al. (2003) and Schaal et al.'s (2000) studies are in accord with such an analysis. Recall that Nevin et al. showed that resistance to change of DMTS accuracy was greater in the component with higher reinforcement probability (.8) than in the component with lower probability (.2). Note that the higher reinforcement probability, the shorter the average 
post-sample delay to reinforcement. Based on Equation 1, therefore, the conditioned reinforcing value of the sample stimulus should be higher in the component with reinforcement probability of .8 .

Recall also that Schaal et al. (2000) showed DMTS accuracy was more resistant to change in the component with the VI 120-s schedule leading to the DMTS trial than in the component with the VI 20-s schedule. Note that the longer the length of the VI schedule, the longer the interreinforcement interval. Based on Equation 1, therefore, the conditioned reinforcing value of the sample stimulus should be higher in the component with the VI 120 -s schedule.

In summary, in terms of behavioral momentum theory, there is a discrepancy between the results of Nevin et al. (2003) and Schaal et al. (2000). In terms of the delay-reduction analysis of DMTS accuracy, on the other hand, there is no such discrepancy. It is important to note, however, that while the delay-reduction analysis is in accord with both studies, the conditioned reinforcing value of the sample stimulus was not measured unambiguously in either study. It was only indirectly measured through DMTS accuracy or by the rate of responding under the VI schedule leading to the DMTS trial (see Williams, 1994, for the problem with this measure in a chain schedule). In addition, as Nevin et al. suggested, it is possible that the Pavlovian stimulusreinforcer contingency is a determining variable of resistance to change of DMTS accuracy and the discrepancy between the two studies could be accounted for by the different types of disruptors employed. They stated, "Research is needed to determine how prefeeding, ICI food, and extinction would affect ... matching accuracy in the procedure of Schaal et al., where components differed in the length of the VI schedules with the same reinforcer probability for correct matches" (p. 318). 


\section{Statement of the Problem}

The primary purpose of the present study was to investigate the role played by the conditioned reinforcing value of the sample stimulus on resistance to change of DMTS accuracy. Two experiments used the multiple chain VI-DMTS chain VI-DMTS paradigm developed by Schaal et al. (2000). In Experiment 1, in line with Nevin et al.'s (2003) suggestion, disruptive effects of commonly used disruptors such as prefeeding and extinction on DMTS accuracy were investigated. In one component of the multiple schedule, the putative conditioned reinforcing value of the sample stimulus was altered by increasing the length of the VI schedule leading to the DMTS trial. The effects of such a manipulation on the conditioned reinforcing value of the sample stimulus were occasionally assessed on probes independently of DMTS accuracy.

Experiment 2 further examined the effects of the conditioned reinforcing value of the sample stimulus on resistance to change of DMTS accuracy. In one component, the putative conditioned reinforcing value of the sample stimulus was altered by superimposing a VT-food schedule on the initial-link VI schedule leading to the DMTS trial (cf. Nevin et al., 1990). It was expected that the superimposed food reduced the conditioned reinforcing value of the sample stimulus by shortening the average interfood interval while keeping the post-sample delay to food reinforcement constant (see Equation 1). The effects of the superimposed food on the conditioned reinforcing value of the sample stimulus also were assessed independently of DMTS accuracy. As in Experiment 1, prefeeding and extinction were used to examine resistance to change of DMTS accuracy.

The use of the VT-food schedule to alter the conditioned-reinforcing value of the sample stimulus in Experiment 2 expands on Experiment 1 for these two reasons. First, by altering the conditioned reinforcing value of the sample stimulus in a different procedure, it allows for the 
assessment of the generality of the finding in Experiment 1. Second, the procedure of altering the conditioned reinforcing value of the sample stimulus by the VT-food delivery eliminates the confounding effects of proactive interference (Grant, 1975) on DMTS accuracy, which could be an issue in Experiment 1. In proactive interference, an event in the past affects the current performance. In a DMTS procedure, for example, proactive interference is alleviated when the trials are spaced (e.g., Grant; Maki, Moe, \& Bierly, 1977). Therefore, if resistance to change of DMTS accuracy is greater in the component in which the trials are spaced more (e.g., increased length of the VI schedule in Experiment 1), the greater resistance to change, if observed, cannot unambiguously be attributed to the enhanced conditioned-reinforcing value of the sample stimulus. Superimposing food on the VI schedule is expected to alter the conditioned reinforcing value of the sample stimulus while trials are equally spaced in time between the components. Therefore, proactive interference is not an issue in Experiment 2.

It is important to note that both increasing the length of the VI schedule (Experiment 1) and superimposing the VT food on the VI schedule (Experiment 2) should alter the conditioned reinforcing value of the sample stimulus and the stimulus-reinforcer Pavlovian contingency in opposite directions. In Experiment 1, for example, increasing the length of the VI schedule in one component should enhance the conditioned reinforcing value of the sample but degrade the Pavlovian contingency in that component. In Experiment 2, superimposing the VT food in one component should reduce the conditioned reinforcing value of the sample stimulus but enhance the Pavlovian contingency in that component. Therefore, a comparison of interest is to examine whether these manipulations enhance or reduce resistance to change of DMTS accuracy. If the resistance to change of DMTS accuracy is governed by the conditioned reinforcing value of the sample stimulus, the resistance should be greater in the component with longer VI length 
(Experiment 1) and in the component without the VT food (Experiment 2). If, however, the resistance to change of DMTS accuracy is governed by the Pavlovian contingency, as behavioral momentum theory suggested, the opposite results should be obtained.

\section{Experiment 1}

Experiment 1 was designed to systematically replicate Schaal et al.'s (2000) study with commonly used disruptors and to examine the relation between resistance to change of DMTS accuracy and the putative conditioned reinforcing value of the sample stimulus. Pigeons were trained on the multiple chain VI-DMTS chain VI-DMTS schedule in which the same reinforcer probability for correct matches was arranged. By systematically manipulating the length of the initial-link VI schedule in one component, the conditioned reinforcing value of the sample stimulus should be altered. Stable DMTS accuracy was disrupted by prefeeding and extinction. The conditioned reinforcing value of the sample stimulus was assessed by occasional probes.

\section{Method}

\section{Subjects}

Four White Carneau pigeons, all with experience on a variety of schedules, served as subjects. The pigeons were maintained at $80 \%$ of their free-feeding weights throughout the experiment via supplemental feedings at least $30 \mathrm{~min}$ after session. The pigeons were housed individually in a temperature-controlled room with a 12:12 hour light/dark cycle. Health grit and water were continuously available in the home cage.

\section{Apparatus}

Experimental sessions were conducted in sound-attenuating operant chambers with the front panels constructed of stainless steel and the walls constructed of either wood or fiberglass and Plexiglas. The experimental space measured $37 \mathrm{~cm}$ high, $30 \mathrm{~cm}$ wide, and $32 \mathrm{~cm}$ deep. 
General illumination was provided by a $28-\mathrm{V}$ houselight (No. 1829) located on either the ceiling of the chamber or the front panel. A resistor, ranging from 200 to $500 \Omega$ depending on the chamber, was switched in and out of the circuit controlling the houselight to allow two levels of intensity (hereafter designated as bright without the resistor and dim with the resistor). Three response keys, approximately $2.5 \mathrm{~cm}$ in diameter, were arranged in a row on the front panel approximately $9 \mathrm{~cm}$ apart from the centers of the keys and $24 \mathrm{~cm}$ from the floor. The keys were illuminated with red, green, or white light from behind by 28-V bulbs (No. 1829) covered with colored caps. Access to mixed grain was provided by raising a food hopper that was accessible through the $5 \mathrm{~cm}$ x $6 \mathrm{~cm}$ aperture located approximately $11 \mathrm{~cm}$ below the center key on the front panel. During the food presentation, the aperture was illuminated by a $28-\mathrm{v}$ bulb (No. 1829) and the houselight and all keys lights were turned off. Noise from a ventilation fan on the side of the chamber helped mask extraneous sounds. All experimental events were controlled and recorded with microcomputers located in an adjacent room.

\section{Procedure}

Throughout the experiment, sessions were conducted 7 days per week at approximately the same time each day. A session lasted until 48 DMTS trials were completed with an exception of resistance to change test sessions, which will be described below.

Preliminary training. The pigeons were initially trained to a high level of accuracy on the DMTS task. A multiple chain VI-DMTS chain VI-DMTS procedure was employed in which the same VI schedules and DMTS trials were arranged in both components. The two multipleschedule components were signaled by the intensity of the houselight, and they alternated regularly after every eight chains. A 30-s ICI separated the components, during which all lights in the chamber were turned off. At the beginning of every other session, either the bright or dim 
houselight was randomly selected for the first component of the session and the other intensity was used at the beginning of the next session. Sessions ended after three presentation of each component.

A component began with onset of the houselight and the white light on the center key. According to a VI 20-s schedule, pecks on the center key turned off the white light and turned on either the red or green light on the center key (sample stimulus). The schedule on the sample stimulus (observing-response requirement) was varied individually and will be described below. After the presentation of the sample stimulus, the side keys were illuminated, one with the red light and the other with the green light (comparison stimuli). A single peck on the comparison stimulus that was the same color as the sample stimulus (matching comparison stimulus) turned off the comparison stimuli and the houselight and raised the food hopper for 2 or $3 \mathrm{~s}$ (individualized for each subject). A single peck on the non-matching comparison stimulus was followed by a 2- or 3-s blackout during which all lights in the chamber were turned off. Throughout the trial, pecks on dark keys had no programmed consequences.

All VI schedules used in this study were composed of a constant-probability distribution of 8 intervals (Fleshler \& Hoffman, 1962). Each interval was randomly selected without replacement. When used in the multiple chain VI-DMTS chain VI-DMTS schedule, separate lists of intervals were maintained for each component.

The DMTS Trials were structured such that the color of the sample stimulus and the position of the red and green comparison stimuli were quasi-randomly determined, with the restriction that four stimulus configurations (e.g., one of the configurations consists of red, red, and green lights on the left, center, and right keys, respectively) were presented equally often in 
blocks of eight trials and that the same stimulus configuration was not presented more than two times in succession.

During the course of preliminary training, either a correction procedure or a forcedchoice procedure with a single comparison stimulus (or both) was temporarily introduced when a pigeon showed position or stimulus biases. In the correction procedure, a peck on a nonmatching comparison stimulus was followed by a 2- or 3-s blackout and the same VI interval and the DMTS trial were repeated until the pigeon pecked on the matching comparison stimulus. In the force-choice procedure with a single comparison stimulus, only a matching comparison stimulus was presented on a trial and the other side key were darkened and inoperative. This was to build a history in which the pigeon consistently received the food reinforcer by pecking both colors of the comparison stimuli on both side keys.

When matching accuracy reached at least $87.5 \%$ in each component for 3 consecutive sessions, a retention interval was imposed between the offset of the sample stimulus and the onset of the comparison stimuli. During the retention interval, the houselight remained on and pecks on dark keys had no programmed consequences. If matching accuracy remained high, duration of the retention interval was incremented for each pigeon up to $4 \mathrm{~s}$. If accuracy decreased, on the other hand, the observing-response requirement was adjusted. All subjects were first exposed to a procedure in which the sample stimulus was presented for a brief period of time (e.g., 2 s) independently of responding. If this fixed-time (FT) schedule failed to maintain high matching accuracy (at least 87.5\%), a fixed-interval (FI) schedule was introduced such that the first response on the sample stimulus after a fixed interval of time (e.g., 2 s) had elapsed turned off the sample stimulus and initiated a retention interval. Finally, if matching accuracy remained low under the FI schedule, a conjunctive FI fixed-ratio (FR) schedule was introduced. 
Under this schedule, the sample stimulus was turned off if the subject met both interval and ratio requirements. For example, when a conjunctive FI 4-s FR 15 schedule was in effect, the 15 th or later response on the sample stimulus after an interval of $4 \mathrm{~s}$ had elapsed turned off the sample stimulus and initiated a retention interval.

The manipulation of duration of retention intervals and observing response requirement continued until matching accuracy was stable around $90 \%$, as judged by visual inspection. The final value of the observing-response requirement and the retention interval for each pigeon is shown on Table 1. 
Table 1. Final procedural parameters of the DMTS trial and the probe for each pigeon in Experiments 1 and 2. "Varied component" refers to the component of the multiple schedule in which the length of the initial-link VI schedule was increased (Experiment 1) or the VT-food schedule was superimposed (Experiment 2). See text for more details.

\begin{tabular}{|c|c|c|c|c|c|c|c|}
\hline \multirow[t]{2}{*}{ Experiment } & \multirow[t]{2}{*}{ Pigeon } & \multicolumn{3}{|c|}{ DMTS Trial } & \multicolumn{3}{|c|}{ Probe } \\
\hline & & $\begin{array}{l}\text { Observing- } \\
\text { Response I } \\
\text { Requirement }\end{array}$ & $\begin{array}{l}\text { Retention } \\
\text { Interval (s) }\end{array}$ & $\begin{array}{l}\text { Reinforcer } \\
\text { Duration (s) }\end{array}$ & $\begin{array}{l}\text { Varied Component } \\
\text { Assigned Position \& } \\
\text { Houselight Intensity }\end{array}$ & $\begin{array}{l}\text { Event that Initiates } \\
\text { Changeover Delay }\end{array}$ & $\begin{array}{c}\text { Food } \\
\text { Delivered }\end{array}$ \\
\hline \multirow[t]{4}{*}{1} & 792 & FT $2 \mathrm{~s}$ & 3 & 2 & Left (Bright) & Last Changeover & No \\
\hline & 2417 & FI $3.5 \mathrm{~s}$ & 2 & 3 & Right (Dim) & Last Changeover & No \\
\hline & 4266 & FI $2 \mathrm{~s}$ & 4 & 3 & Left (Bright) & Last Changeover & No \\
\hline & 6994 & FI $4.5 \mathrm{~s} \&$ FR 15 & 1 & 3 & Right (Dim) & Last Changeover & Yes \\
\hline \multirow[t]{3}{*}{2} & 6693 & FT $4 \mathrm{~s}$ & 0.1 & 2 & Right (Dim) & Last Changeover & No \\
\hline & 9297 & FI $5 \mathrm{~s}$ & 0.1 & 2 & Right (Dim) & Last Changeover & Yes \\
\hline & 9980 & FT $4 \mathrm{~s}$ & 0.1 & 2 & Left (Bright) & Last Response & No \\
\hline
\end{tabular}


Baseline. As with the preceding preliminary training, the multiple chain VI-DMTS chain VI-DMTS procedure operated with each component consisting of eight chains. The procedure differed from the previous phase in three ways: implementation of a forced-choice procedure, introduction of probes to assess the conditioned reinforcing value of the sample stimuli, and manipulation of the VI schedule leading to the DMTS trial.

First, for the duration of the experiment, a forced-choice procedure was implemented such that pecks on the non-matching comparison stimulus had no programmed consequences. Therefore, a trial did not proceed until the pigeon pecked the matching comparison stimulus. Note that this forced-choice procedure differed from the one in preliminary training, in that the non-matching comparison stimulus was also presented. This procedure was designed to keep the obtained delays between the sample onset and the delivery of food reinforcer close to the programmed delays even if matching accuracy decreased (Schaal et al., 2000). Only the first peck on either of the comparison stimuli was used for the calculation of matching accuracy.

Second, probes to assess the conditioned reinforcing value of the sample stimuli were conducted. The goal was to assess the value of the sample stimuli in the context of each multipleschedule component (as signaled by the bright or dim houselight). Following a 30-s ICI, a block of two probes was conducted after each component except for the first and second components. This was to ensure that the pigeons were exposed to the sample stimuli in both components before the probes were conducted.

A probe was composed of a concurrent-chains schedule. In the initial links, both side keys were illuminated with the white light and the houselight was turned off. A single VI 20-s schedule was in effect. A terminal-link entry was assigned quasi-randomly to either the left or right key, with the restriction that terminal-link entries were assigned to both keys equally often 
in a session (Stubbs \& Pliskoff, 1969). Once the VI interval elapsed and if at least $2 \mathrm{~s}$ had elapsed since the last changeover to the side key to which a terminal-link entry was assigned, the next peck on the assigned side key darkened both side keys and a terminal link began. The entry to the terminal link was signaled by the presentation of the bright or dim houselight, depending on the side key through which a terminal link was entered. Either the red or green light was presented quasi-randomly on the center key, with the restriction that both colors were presented equally often within a session. A single peck on the center key turned off the houselight and the light on the center key, which was followed by a 2- or 3-s blackout and then either the next probe or a 30-s ICI.

During the initial phase of the baseline condition in which the VI schedules leading to the DMTS trials were identical between the two components, the entry to the terminal link by the left and right keys was signaled by the presentation of the bright and dim houselights, respectively (with the exception of Pigeon 6994 for which the relation between the position of the side keys and the intensity of the houselight was reversed). During the subsequent conditions in which the VI schedules leading to the DMTS trials were different between components, on the other hand, the relation between the position of the side keys and the intensity of the houselight was determined based on each pigeon's response allocation between the left and right keys during the initial phase of the baseline condition. For example, if a pigeon showed a bias toward the left key that led to the presentation of the bright houselight during terminal links, the bright houselight was correlated with the sample stimuli that are assumed to have lower conditioned reinforcing value in the multiple chain VI-DMTS chain VI-DMTS schedule. Table 1 shows the assignment of the position and intensity of houselight for each pigeon. 
Some pigeons stopped responding during the initial or terminal link of a probe and the session could not continue. Thus, some procedural changes were made either permanently or temporarily. For example, a limited hold contingency was placed such that the terminal-link stimuli were presented after 5 min independently of responding. Once introduced, the limited hold contingency was retained throughout the experiment. As Pigeon 6994 often stopped responding during the terminal link, food was delivered contingent on a single peck on the center key during the terminal link. In addition to these permanent changes, some other procedural changes were made temporarily. For example, to increase the response rate during the initial link of the probes, the length of the VI schedule was reduced to $10 \mathrm{~s}$. If the response rate remained low, the event that initiated a changeover delay was altered such that at least $2 \mathrm{~s}$ had to elapse since the last response to the side key to which a terminal-link entry was not assigned, rather than since the last changeover to the side key to which a terminal-link entry was assigned.

It is assumed that, during the probes, the response allocation between the left and right keys during the initial links is determined by the conditioned reinforcing value of the sample stimuli in context (as defined by the intensity of the houselight) presented during the terminal links. Note that the stimulus configuration of the terminal link (e.g., the red light on the center key in the context of the bright houselight) was the same as that of the sample stimulus in DMTS trials. The sample stimuli were correlated with different delays to food reinforcement in the context of the bright and dim houselights under the multiple chain VI-DMTS chain VI-DMTS schedule. According to the delay reduction hypothesis, the differential reduction in delay to food reinforcement between components should produce the difference in the conditioned reinforcing value of the sample stimuli between components. This difference in the value of the sample stimuli, in turn, should be reflected on the response allocation between the left and right keys 
during the initial links (see O'Daly, Meyer, \& Fantino, 2005, for empirical validation with a similar procedure).

Finally, the VI schedules leading to the DMTS trial were systematically manipulated between the two components of the multiple schedule. Once performance stabilized (described below), the length of the VI schedule in one component was altered to increase the difference in the conditioned reinforcing value of the sample stimuli between the two components (see Table 2 for the length of the VI schedule of each experimental condition). This manipulation continued until there was a clear difference between the components in (a) the rate of responding under the initial-link VI schedule leading to the DMTS trial, (b) matching accuracy, and (c) the response allocation during the probes, as judged by visual inspection. Once all resistance-to-change tests (described below) were conducted, some conditions were repeated in some subjects.

There were two exceptions for this manipulation of the VI schedules. First, Pigeon 2417 was exposed to resistance-to-change tests although the response allocation during the probes was not affected by the manipulation of the VI schedule. Even when the difference in the length of the VI schedule between the components was large (e.g., VI 8 s vs. VI 313 s), this pigeon showed strong position bias during the probes. Second, Pigeon 6994 was exposed to the second prefeeding test (described below) although the rates of responding under the initial-link VI schedule did not differentiate between components.

The performance was considered as stable if there was no upward or downward trend in the three dependent measures during the last 5 sessions, as judged by visual inspection. 
Table 2. Initial-link VI schedules, number of sessions, and tests of resistance to change for each pigeon in Experiment 1.

\begin{tabular}{|c|c|c|c|c|c|}
\hline \multirow{2}{*}{ Pigeon } & \multirow[t]{2}{*}{ Condition } & \multicolumn{2}{|c|}{ Initial-Link VI Schedule (s) } & \multirow[t]{2}{*}{ Sessions } & \multirow{2}{*}{$\begin{array}{c}\text { Test of Resistance to } \\
\text { Change }\end{array}$} \\
\hline & & $\begin{array}{c}\text { Bright } \\
\text { Houselight }\end{array}$ & $\begin{array}{l}\text { Dim } \\
\text { Houselight }\end{array}$ & & \\
\hline \multirow[t]{6}{*}{792} & 1 & 20 & 20 & 28 & Prefeeding for 5 sessions \\
\hline & 2 & 50 & 20 & 37 & - \\
\hline & 3 & 125 & 20 & 22 & Prefeeding for 5 sessions \\
\hline & 4 & 125 & 20 & 24 & Extinction for 9 sessions \\
\hline & 5 & 20 & 20 & 50 & Prefeeding for 5 sessions \\
\hline & 6 & 125 & 20 & 33 & - \\
\hline \multirow[t]{7}{*}{2417} & 1 & 20 & 20 & 65 & Prefeeding for 5 sessions \\
\hline & 2 & 20 & 50 & 22 & - \\
\hline & 3 & 20 & 125 & 66 & - \\
\hline & 4 & 20 & 313 & 24 & - \\
\hline & 5 & 8 & 313 & 21 & Prefeeding for 5 sessions \\
\hline & 6 & 8 & 13 & 41 & Extinction for 14 sessions \\
\hline & 7 & 8 & 8 & 26 & Prefeeding for 5 sessions \\
\hline \multirow[t]{6}{*}{4266} & 1 & 20 & 20 & 43 & Prefeeding for 5 sessions \\
\hline & 2 & 50 & 20 & 24 & - \\
\hline & 3 & 125 & 20 & 25 & Prefeeding for 5 sessions \\
\hline & 4 & 125 & 20 & 28 & Extinction for 20 sessions \\
\hline & 5 & 20 & 20 & 79 & Prefeeding for 5 sessions \\
\hline & 6 & 20 & 125 & 33 & - \\
\hline \multirow[t]{3}{*}{6994} & 1 & 20 & 20 & 128 & Prefeeding for 5 sessions \\
\hline & 2 & 20 & 50 & 27 & - \\
\hline & 3 & 20 & 125 & 100 & Prefeeding for 5 sessions \\
\hline
\end{tabular}


Resistance tests. To investigate the resistance to change of matching accuracy as well as the rate of responding under the initial-link VI schedule leading to the DMTS trial, in some conditions the stable performance was disrupted by prefeeding and extinction. The order of experimental conditions is shown in Table 2.

In the prefeeding test, each pigeon was fed either in the home cage or in a cage placed in a quiet experimental room $30 \mathrm{~min}$ before the session on 5 consecutive days. The amount of food given on successive days was $20 \mathrm{~g}, 30 \mathrm{~g}, 40 \mathrm{~g}, 40 \mathrm{~g}$, and $40 \mathrm{~g}$. As the pigeons rarely consumed as much as $40 \mathrm{~g}$ during the final three days, the actual amount they consumed was measured after 30 min and shown on Table 3. The prefeeding test was conducted three times (except for Pigeon 6994). The first and third tests were conducted when the length of the VI schedule was the same between the components (i.e., a VI $20 \mathrm{~s}$ in both components). The second test was conducted after the difference in the dependent measures between the components emerged (e.g., a VI $20 \mathrm{~s}$ in one component and a VI $125 \mathrm{~s}$ in the other component).

Table 3. Amount of food consumed (g) during prefeeding sessions in Experiments 1 and 2.

\begin{tabular}{|c|c|c|c|c|c|c|c|c|c|c|c|c|c|c|c|c|}
\hline \multirow[t]{2}{*}{ Exp } & \multirow[t]{2}{*}{ Pigeon } & \multicolumn{5}{|c|}{ First Test } & \multicolumn{5}{|c|}{ Second Test } & \multicolumn{5}{|c|}{ Third Test } \\
\hline & & 1 & 2 & 3 & 4 & 5 & 1 & 2 & 3 & 4 & 5 & 1 & 2 & 3 & 4 & 5 \\
\hline \multirow[t]{4}{*}{1} & 792 & 20 & 30 & 37 & 37 & 25 & 20 & 30 & 40 & 16 & 37 & 20 & 30 & 39 & 26 & 40 \\
\hline & 2417 & 20 & 30 & 38 & 15 & 34 & 20 & 30 & 13 & 27 & 18 & 20 & 30 & 8 & 34 & 19 \\
\hline & 4266 & 20 & 30 & 36 & 19 & 30 & 20 & 30 & 38 & 18 & 26 & 20 & 30 & 31 & 18 & 24 \\
\hline & 6994 & 20 & 30 & 40 & 28 & 21 & 20 & 30 & 40 & 9 & 37 & - & - & - & - & - \\
\hline \multirow[t]{3}{*}{2} & 6693 & 20 & 30 & 40 & 40 & 20 & 20 & 30 & 12 & 19 & 11 & - & - & - & - & - \\
\hline & 9297 & 20 & 30 & 40 & 40 & 33 & 20 & 30 & 40 & 15 & 19 & - & - & - & - & - \\
\hline & 9980 & 20 & 30 & 25 & 22 & 35 & 20 & 30 & 19 & 17 & 24 & - & - & - & - & - \\
\hline
\end{tabular}


In the extinction test, the food reinforcer was discontinued. The first peck on either of the comparison stimuli was followed by a 2- or 3-s blackout. The extinction test continued for a maximum of 20 sessions or until the following criterion was met: during two consecutive sessions, (a) the rate of responding under the initial-link VI schedule in at least one component was reduced to less than $10 \%$ of the preceding baseline condition and (b) less than $10 \%$ of DMTS trials in at least one component were completed (as defined by a response to the comparison stimulus).

During both disruption tests, some procedural changes were made to ensure that the pigeons were exposed to every chain of the session. First, if no peck on the center key occurred for $20 \mathrm{~s}$ plus the longest interval of the VI schedule in effect (e.g., $81.3 \mathrm{~s}$ for a VI $20 \mathrm{~s}$ ), the sample stimulus was presented independently of responding. Exceptions were the first prefeeding test for all pigeons and the second prefeeding test for Pigeon 4266. If no response occurred for $20 \mathrm{~s}$ plus the longest interval from the onset of a trial, the sample stimulus was presented independently of responding. Second, if an FI schedule was in effect on the sample stimulus and no peck on the sample stimulus occurred for $20 \mathrm{~s}$ plus the interval of the FI schedule, the sample stimulus was turned off and the retention interval began. Finally, if no peck on the matching comparison stimulus occurred for $20 \mathrm{~s}$, the comparison stimuli were turned off and a 3-s blackout followed. If a DMTS trial ended without responding on the comparison stimulus, the trial was excluded from the calculation for matching accuracy. All other procedural details during the disruption tests were identical to those during the preceding baseline condition.

Measures. The primary measures were rate of responses during the initial link of the chain schedule, matching accuracy, and response allocation during the probes. These measures were calculated separately for both components. 
First, the rate of responses during the initial link was calculated by dividing the number of center-key pecks in the presence of the white stimulus by the time in which the white stimulus was presented. This excludes the time of DMTS trials, reinforcement deliveries, timeouts, and ICIs. Second, matching accuracy was expressed as $\log d$. This measure has been used frequently in the analysis of conditional discrimination such as DMTS and is calculated in this manner:

$$
\log d=0.5 \log \left[\left(C_{11} / C_{12}\right)\left(C_{21} / C_{22}\right)\right]
$$

where $C_{11}$ and $C_{12}$ refer to the number of choices of Comparisons 1 and 2, respectively, following Sample 1, and $C_{21}$ and $C_{22}$ refer to the number of choices of Comparisons 1 and 2, respectively, following Sample 2. Note that this measure is the logarithm of the geometric mean of the ratio of correct to incorrect choices on trials involving Samples 1 and 2. As $\log d$ cannot be calculated if any of the terms is zero, 0.25 was added to all of the terms before calculating $\log d$ (see Brown \& White, 2005a; Hautus, 1995, for the rationale). The main advantages of $\log d$ are that it is conceptualized as a measure of the discriminability of the sample stimuli at the time of the comparison selection (White, 1985), and that it is independent of biases (Davison \& Nevin, 1999) that may occur during the disruption test. Finally, the response allocation during the probes was calculated by dividing the number of responses on the side key that produces the sample stimuli associated with greater delay to reinforcement by the total number of responses on both side keys.

\section{Results}

Figure 1 shows mean response rates $(+1 \mathrm{SD})$ during the VI initial links leading to the DMTS trial across the last five sessions of each condition. The black bars show response rates in the component in which the length of the VI schedule was varied (hereafter varied component). The gray bars show response rates in the component in which the VI schedule remained constant 
(hereafter constant component). In two pigeons (Pigeons $792 \& 2417$ ), the response rates in the constant component did not change systematically across conditions, whereas those in the varied component were inversely related to the length of the VI schedule. In Pigeon 4266, the response rates in both components somewhat decreased as experimental conditions proceeded. In Pigeon 6994, on the other hand, the response rates in neither component were systematically affected by the VI schedules in effect. In this pigeon, response rates in both components decreased drastically when the VI 125-s schedule was arranged in the varied component.

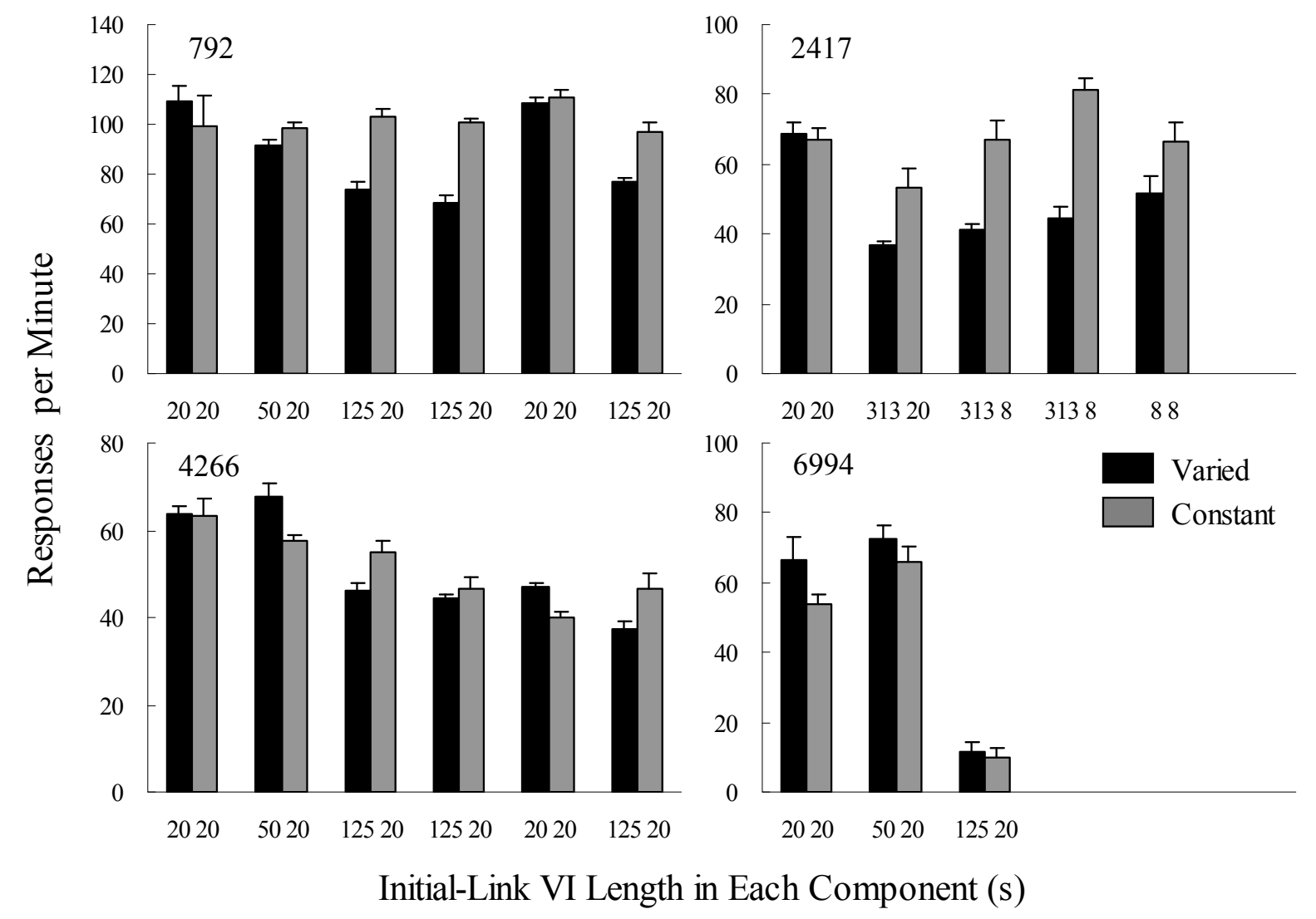

Figure 1. Mean rates of responses per minute as a function of the initial-link VI length in Experiment 1. The black bars show rates of responses in the component in which the VI schedule was varied across conditions. The gray bars show rates of responses in the component in which the length of the VI schedule remained constant. The numbers below bars indicate the length of the VI schedule arranged in each component. Error bars represent one standard deviation. 
The left panel of Figure 2 shows mean $\log d(+1 \mathrm{SD})$ across the last five sessions of each condition. As with Figure 1, the black and gray bars show $\log d$ in the varied and constant components, respectively. Comparisons across conditions indicate that, in three of the four pigeons (Pigeons 792, 2417, \& 4266), $\log d$ in the varied component improved when the length of the VI schedule was increased. On the other hand, $\log d$ in the constant component decreased despite the fact that the VI schedule in the constant component was unchanged. As shown on the right panel of Figure 2, this contrast effect is more evident when $\log d$ is expressed as a proportion of $\log d$ of the first condition in which the same VI schedule was arranged in both components. An exception was Pigeon 6994. The contrast was not observed in this pigeon. Nevertheless, as with other pigeons, $\log d$ was higher in the component with the VI 125-s schedule than in the component with the VI 20-s schedule. 

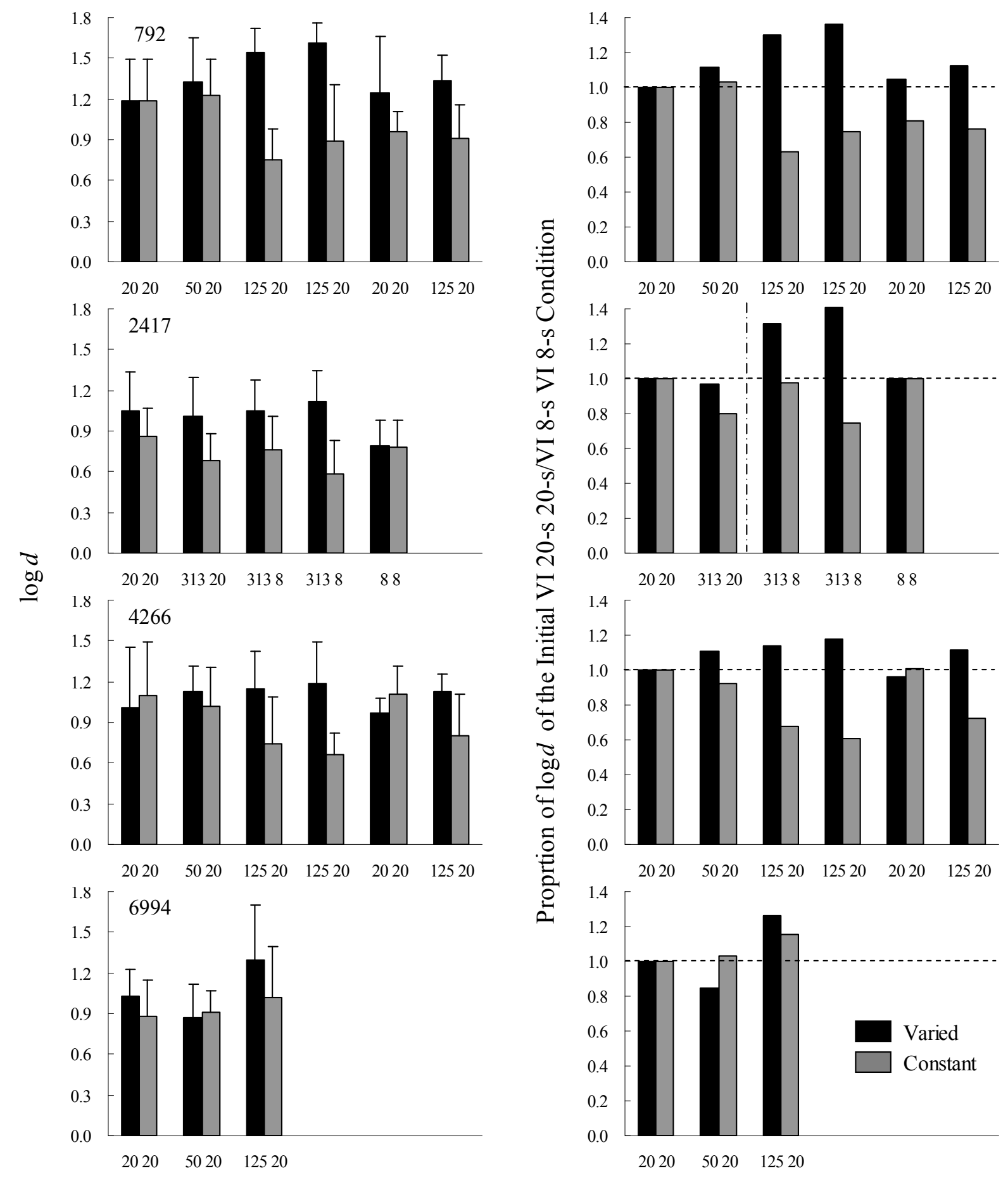

Initial-Link VI Length in Each Component (s)

Figure 2. Mean $\log d$ (left panel) and $\log d$ expressed as a proportion of the first condition with the same VI schedules in both components (right panel) as a function of the initial-link VI length in Experiment 1. For Pigeon 2417, the graphs plotted to the left and right of the dashed vertical line show a log proportion of the conditions with the VI 20-s and VI 8-s schedule arranged in both components, respectively. The black bars show $\log d$ in the component in which the length 
of the VI schedule was varied across conditions. The gray bars show log $d$ in the component in which the length of the VI schedule remained constant. The numbers below bars indicate the length of the VI schedule arranged in each component. Error bars represent one standard deviation.

Figure 3 shows mean choice proportion (+1 SD) during the probes across the last five sessions of each condition. In general, all pigeons allocated more responses to the alternative leading to the sample stimuli correlated with greater reduction in delay to food reinforcement as the length of the VI schedule in one component increased. This is shown by the value of the choice proportion exceeding 0.5 . As choice proportion is considered to be determined by the value of the stimuli presented immediately after the choice phase, the greater choice proportion shows that the value of the sample stimuli was higher in the component with a longer VI schedule leading to the DMTS trial. There were some individual variations, however, that are inconsistent with this general finding. In Pigeon 2417, the value of the choice proportion remained below 0.5 in the third condition in which the VI 313-s and VI 8-s schedules were arranged in the varied and constant components, respectively. Nevertheless, the value exceeded 0.5 when the same VI schedules were repeated in the subsequent condition. In Pigeon 4266, the choice proportion did not shift toward indifference in the fifth condition in which the VI 20 -s schedule was arranged in both components. Thus, the assignment of the samples with greater delay reduction was switched from the left to the right side key in the subsequent condition in which the length of the VI schedule in the varied component was again increased to $125 \mathrm{~s}$. The choice proportion for sample stimuli correlated with greater delay reduction decreased abruptly. This was because the pigeon continued responding almost exclusively to the left side key during the choice phase of the probes, regardless of the sample stimuli presented. 


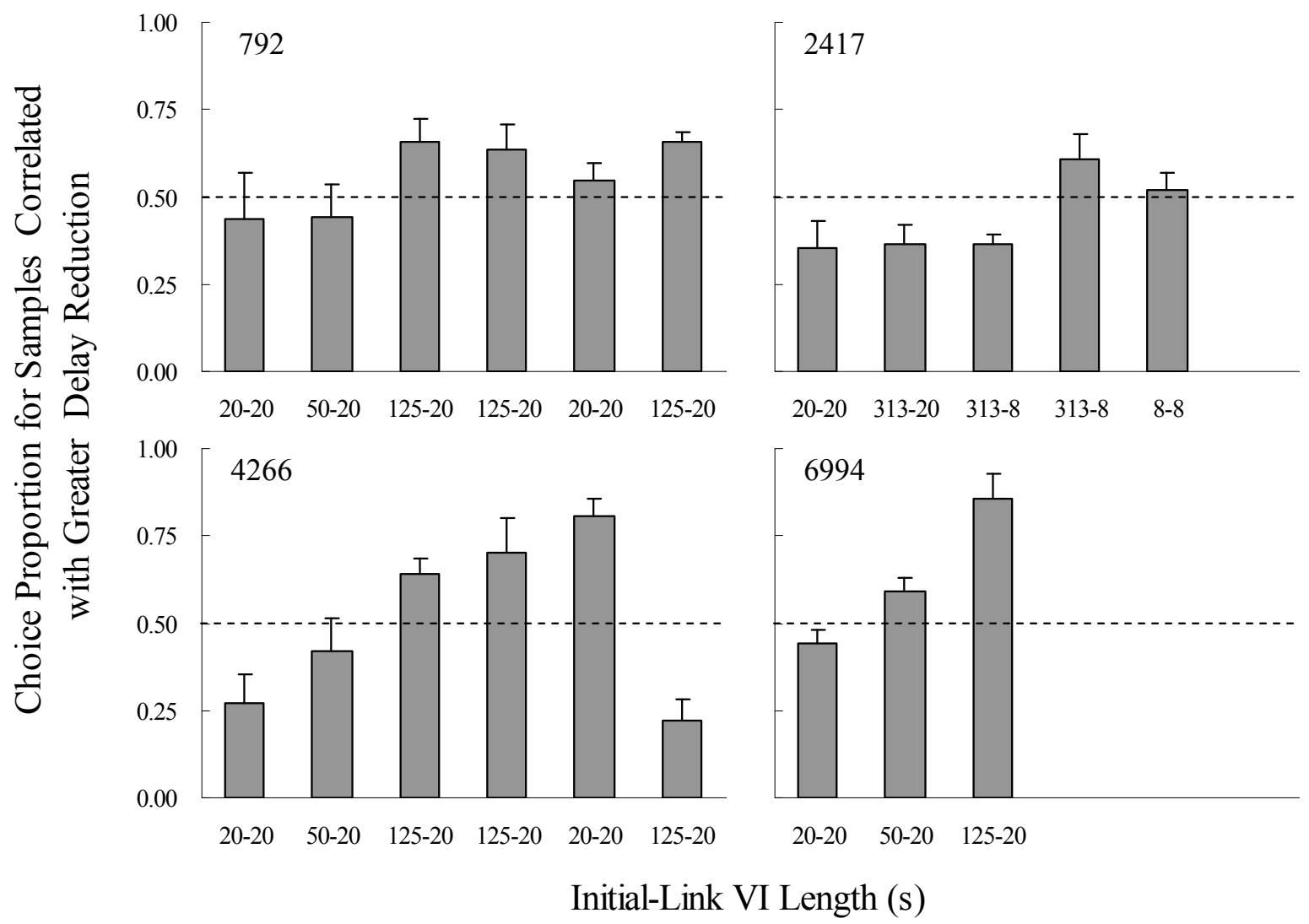

Figure 3. Mean choice proportion for sample stimuli correlated with greater reduction in delay to reinforcement during the probes as a function of each experimental condition in Experiment 1. The numbers connected to the left and right of a hyphen below gray bars indicate the length of the VI schedule of the varied and constant components, respectively. Error bars represent one standard deviation.

Figure 4 show response rates during the tests of resistance to change. The response rates during the VI initial links are expressed as a log proportion of the mean response rate of the last five baseline sessions immediately before each test over successive test sessions. Because log proportion values cannot be calculated when responding was completely suppressed, the lowest value of the log proportions was set to -2.0 .

The first and last rows of Figure 4 show the results from the prefeeding test following the baseline sessions in which the VI schedules were the same in both components. There was no systematic difference in resistance to prefeeding between the two components. In all pigeons, responding in the two components decreased at almost equal rates as test sessions proceeded. 
The second and third rows show the results from the prefeeding and extinction test, respectively, following the baseline sessions in which the initial-link VI schedules differed between components. In six out of the seven cases (except for Pigeon 792's extinction test), resistance to both prefeeding and extinction was greater in the component with the shorter VI schedule, although in some cases the difference was small (e.g., Pigeon 4266's prefeeding test).
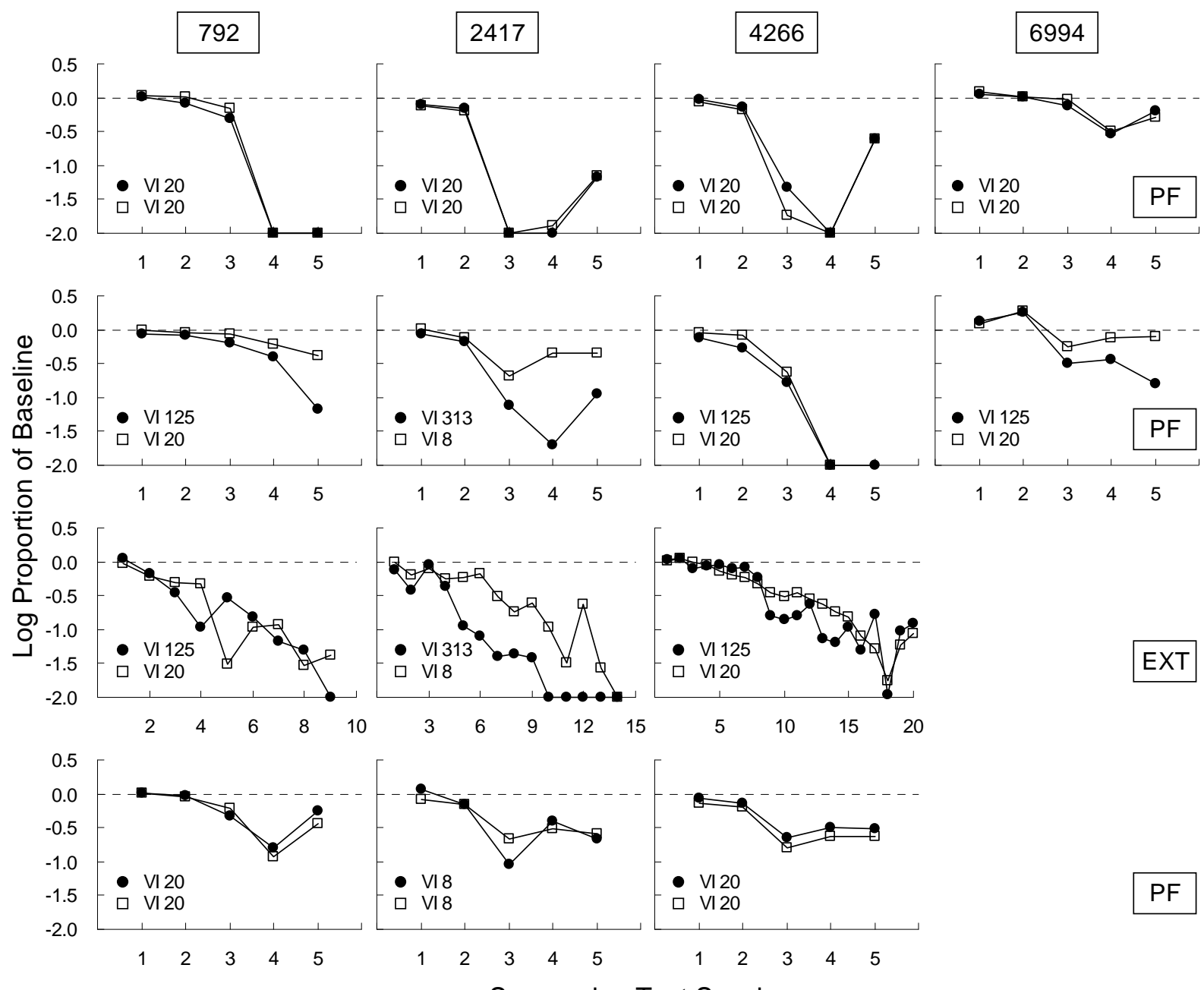

Figure 4. Response rates during the VI initial links expressed as a log proportion of the mean of the last five baseline sessions immediately prior to each resistance to change test as a function of successive test sessions in Experiment 1. Closed circles represent log proportions of response rates in the component in which the length of the VI schedule was varied. Open squares represent log proportions of response rates in the component in which the length of the VI schedule remained constant. "PF" and "EXT" refer to prefeeding and extinction tests, respectively. 
Figure 5 shows DMTS accuracy during the tests of resistance to change. $\log d$ is expressed as a log proportion of the mean of the last five baseline sessions over a moving window of three blocks of eight successive DMTS trials (one data point of the figure represents 24 DMTS trials). As mentioned earlier, a DMTS trial proceeded even without responding. Thus, only trials in which the pigeon pecked the comparison stimulus are included for analysis. If a block does not contain at least six trials (out of eight trials), such a block was excluded for analysis (mean numbers of trials excluded for analysis were 1.4, 0.3, 2.1, and 0.0 for Pigeons 792, 2417,4266 , and 6994 , respectively, in each component during a test). This adjustment was necessary because the value of $\log d$ is affected by the number of trials used for calculation, even if a proportion of correct trials is the same. As log proportion values cannot be calculated if the value of $\log d$ is equal to or lower than zero, at which point the sample stimuli exert no stimulus control, the lowest value was set to -1.5 .

In one pigeon (Pigeon 792), DMTS accuracy in both components was deteriorated at almost equal rates over successive DMTS trials when the components contained equal VI schedules (the first and last rows). On the other hand, DMTS accuracy was deteriorated more slowly in the component with the VI 20-s schedule than that in the component with the 120-s schedule in both prefeeding (the second row) and extinction (the third row) tests. That is, matching accuracy was more resistant to disruption in the component with the VI 20-s schedule leading to the DMTS trials than in the component with the VI 125-s schedule. In the other three pigeons, however, no such an effect was observed. Resistance to change of matching accuracy was not systematically affected by the preceding VI schedules. An exception was Pigeon 4266 . During the prefeeding (the second row) and extinction (the third row) tests, DMTS accuracy was somewhat more resistant to change in the component with the VI 125-s schedule than in the 
component with the VI 20-s schedule. However, DMTS accuracy was also resistant to change in the varied component (represented by closed circles) during the third prefeeding test (the last row) in which the components contained equal VI schedules. Therefore, the greater resistance to change in the component with the VI 125-s schedule observed during the second prefeeding and extinction tests cannot be unambiguously attributed to the different length of the VI schedules.
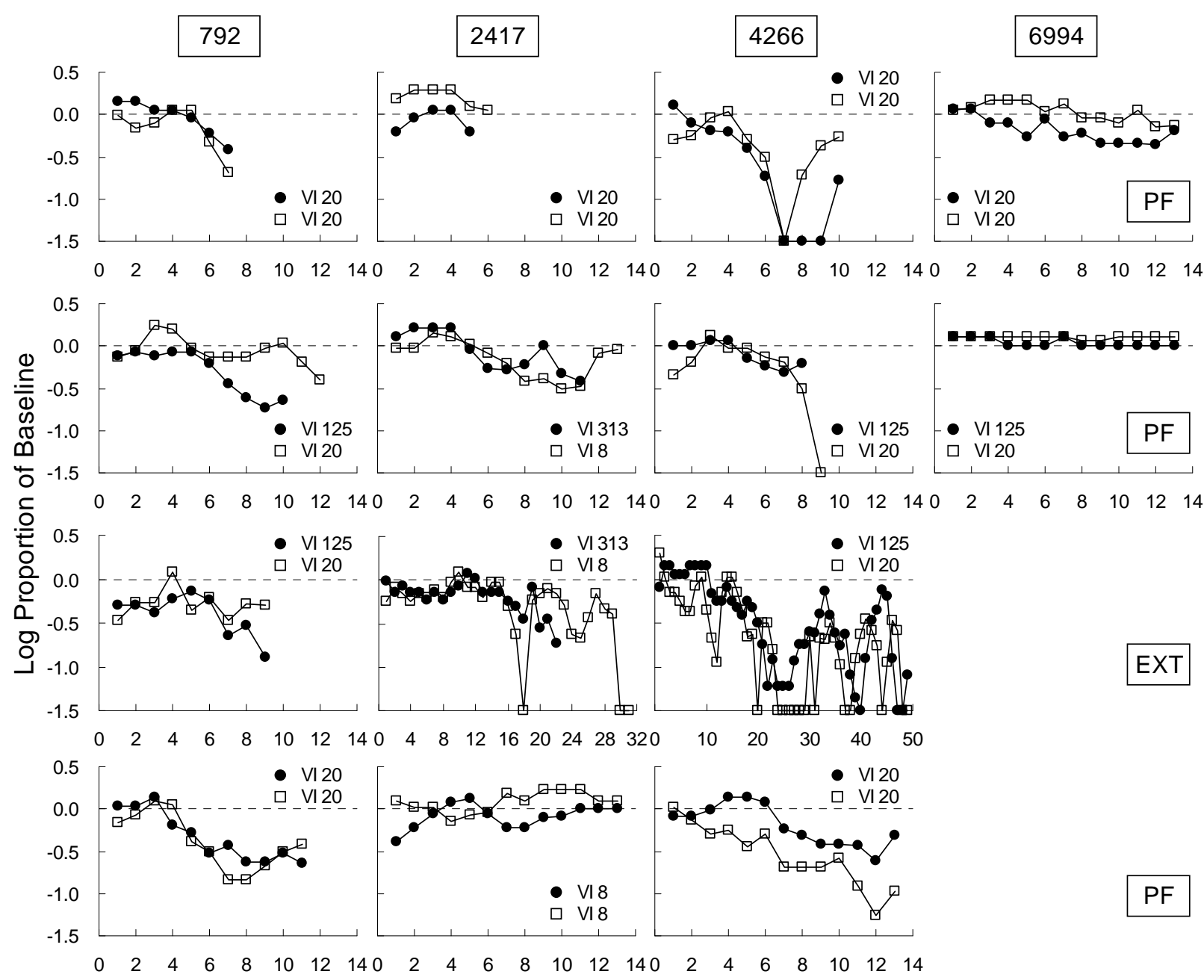

Moving Window of 3 Blocks of 8 DMTS Trials

Figure 5. Log $d$ expressed as a $\log$ proportion of the mean of the last five baseline sessions immediately prior to each resistance to change test as a function of a moving window of three blocks of eight DMTS trials in Experiment 1. Closed circles represent log proportions in the component in which the length of the VI schedule was varied. Open squares represent log proportions in the component in which the length of the VI schedule remained constant. "PF" and "EXT" refer to prefeeding and extinction tests, respectively. 


\section{Discussion}

In Experiment 1, the length of the initial-link VI schedule leading to the DMTS trial in one of the two components was manipulated to alter the conditioned reinforcing value of the sample stimuli. During baseline, response rates during the initial link in the varied component were inversely related to the length of the VI schedule, whereas DMTS accuracy expressed as $\log d$ in the same component was directly related. During tests of resistance to change, stable performance was disrupted by prefeeding and extinction. In all pigeons, response rates were more resistant to change in the component with the shorter VI schedule. Resistance to change of DMTS accuracy was greater in the component with the shorter VI schedule in one pigeon, whereas the length of the VI schedule had no consistent effects on resistance to change of DMTS accuracy in the other three pigeons.

The observation that DMTS accuracy was higher in the component with the longer VI schedule is consistent with previous studies (e.g., Hartl et al., 1996; Roberts \& Kraemer, 1982; Schaal et al., 2000). None of these studies, however, assessed the conditioned reinforcing value of the sample stimuli independently of the DMTS task. The results of the probes in the present study showed that the pigeons preferred the alternative leading to sample stimuli correlated with greater reduction in delay to food reinforcement. This indicates that lengthening the VI schedule actually enhanced the value of the sample stimuli as a conditioned reinforcer. Therefore, these results are in general agreement with the delay-reduction analysis of DMTS accuracy proposed by Wixted (1989). According to the analysis, DMTS accuracy is a function of the value of the sample stimuli as a conditioned reinforcer, as determined by relative reduction in delay to food reinforcement. An important contribution of the present study is that by directly assessing the 
value of the sample stimuli, the results provided empirical evidence that DMTS accuracy and the conditioned reinforcing value of the sample stimuli covaried.

The primary purpose of Experiment 1, however, was to systematically replicate Schaal et al.’s (2000) study with commonly used disruptors such as prefeeding and extinction and to examine the relation between resistance to change of DMTS accuracy and the conditioned reinforcing value of the sample stimulus. The results of the prefeeding and extinction tests show that resistance to change of DMTS accuracy was not systematically related to the conditioned reinforcing value of the sample stimuli. These results are inconsistent with those of Schaal et al. In their study, greater resistance to change was observed in the component in which the conditioned reinforcing value of the sample stimuli was higher. Recall that Schaal et al. used increasing delay between sample offset and comparison onset as a disruptor, whereas the present study used conventional disruptors such as prefeeding and extinction. Therefore, the discrepancy between Schaal et al's study and the present study should be attributed to the different types of disruptors used.

Recall also that the conditioned reinforcing value of the sample stimuli and rate of primary reinforcement were placed in opposition in the present study. That is, in the component in which the conditioned reinforcing value of the sample stimuli was higher, the rate of primary reinforcement was lower, and vice versa. The results of the present study, that resistance to change of DMTS accuracy was greater in the component with higher primary reinforcement rate, are consistent with those of Nevin and his colleagues (e.g., Nevin et al., 2003). The results of both studies are in accord with behavioral momentum theory stating that resistance to change is governed by rate of primary reinforcement rate. 
Cautions should be made, however. In the present study, only one pigeon's data are consistent with behavioral momentum theory. The failure to demonstrate differential resistance to change of DMTS accuracy in the other three pigeons may indicate that the variable of interest was ineffective. That is, the difference in the length of the initial-link VI schedule between components was not sufficiently large such that the subsequent difference in a Pavlovian stimulus-reinforcer contingency did not impact resistance to change. There are at least two pieces of evidence, however, that argue against this possibility. First, multiple measures during baseline (e.g., choice proportion during probes and baseline DMTS accuracy) show that the difference between components did impact baseline performance. Second and more directly, for all pigeons, greater resistance to change of responding during the initial links was observed in the component with the shorter VI schedule (Figure 4). This indicates that the difference in the length of the VI schedule between components was sufficiently large to impact resistance to change.

Alternatively, the lack of differential resistance to change of DMTS accuracy between two components might have been due to the third variable other than the conditioned reinforcing value of the sample stimuli and rate of primary reinforcement. For example, lengthening the VI schedule leads to longer spacing between DMTS trials. A number of studies have demonstrated that effects of proactive interference, which could lower DMTS accuracy, are alleviated when the trials are spaced longer (e.g., Grant, 1975; Maki, Moe, \& Bierly, 1977). While the relation between proactive interference and resistance to change of DMTS accuracy is unknown, it may be possible that longer between-trial spacing in the component with the longer VI schedule might have increased DMTS accuracy in that component. This, in turn, might have masked the effects of higher rate of primary reinforcement on resistance to change that are to be detected otherwise. Experiment 2 was designed to examine this possibility. 


\section{Experiment 2}

The purpose of Experiment 2 was to examine further the relation between the conditioned reinforcing value of the sample stimuli and resistance to change of DMTS accuracy. As in Experiment 1, pigeons were trained on the multiple chain VI-DMTS chain VI-DMTS schedule. The same VI schedules were arranged in both components. The conditioned reinforcing value of the sample stimuli in one component was altered by superimposing a VT food schedule on the VI schedule. Stable DMTS accuracy was disrupted by prefeeding and extinction. The conditioned reinforcing value of the sample stimuli also was assessed on occasional probes.

\section{Method}

\section{Subjects and Apparatus}

Four White Carneau pigeons with various experimental histories served as subjects. The pigeons were different from those used in Experiment 1. One pigeon died during the course of the preliminary training and the data for the pigeon were not reported here. Care of the pigeons was the same as described in Experiment 1. The apparatus was similar, except that in three of the four chambers the response keys are approximately $2.0 \mathrm{~cm}$ in diameter and in all four chambers the keys were illuminated with blue, green, or white light.

\section{Procedure}

Preliminary training was the same as described in Experiment 1, except that (a) blue and green were used as the sample and comparison stimuli on DMTS trials, (b) the duration of the retention interval and food presentation, respectively, was 0.1 and $2 \mathrm{~s}$ for all pigeons, and (c) the length of a VI schedule leading to the DMTS trial was $60 \mathrm{~s}$ in both components. The length of a VI schedule was selected such that the current procedure approximates Nevin et al.'s (1990) baseline procedure and the results of both studies can be compared as directly as possible. As in 
Experiment 1, some procedural parameters were manipulated, either temporarily or permanently, to maintain high matching accuracy on DMTS trials and steady responding during probes. For example, for Pigeon 9297, the observing-response requirement was changed from a VT to a VI schedule, and food was delivered on completion of the terminal link requirement. For Pigeon 9980, the calculation of a changeover delay started timing at the occurrence of the last response to either side key. The final values of these procedural parameters for each pigeon are shown in Table 1.

In Experiment 2, the delay-reduction associated with the sample stimuli in one component of the multiple schedule was altered by superimposing a VT food schedule during the VI initial links. Once the first resistance to prefeeding test was completed, the schedule leading the DMTS trial in one component was changed to a concomitant VI 60-s VT $n$-s food schedule, where the value of $n$ was changed across conditions (see Table 4). In a concomitant VI 60-s VT 15-s food schedule, for example, pecks on the center key produced the DMTS trial according to the VI 60-s schedule, while food was delivered independently of responding according to the VT 15-s schedule. The VT schedule consisted of a constant-probability distribution of 8 intervals (Fleshler \& Hoffman, 1962) with each interval randomly selected without replacement. The VT schedule became richer until there was a clear difference between the components in (a) the rate of responding under the initial-link VI schedule, (b) matching accuracy, and (c) the response allocation during the initial links of the probes, as judged by visual inspection. An exception was Pigeon 6993's response allocation during the probes. The measure was not sensitive to the manipulation of the VT schedule even when the schedule was as rich as a VT $7.5 \mathrm{~s}$. 
Table 4. The VT-food schedule superimposed on the initial-link VI schedule, number of sessions, and tests of resistance to change for each pigeon in Experiment 2. During the first extinction test (Extinction 1), the VT-food schedule was retained but no food was delivered on completion of the DMTS trial. During the second extinction test (Extinction 2), all food delivery was discontinued.

\begin{tabular}{|c|c|c|c|c|c|}
\hline \multirow[t]{2}{*}{ Pigeon } & \multirow[t]{2}{*}{ Condition } & \multicolumn{2}{|c|}{ VT Schedule (s) Added } & \multirow[t]{2}{*}{ Sessions } & \multirow{2}{*}{$\begin{array}{c}\text { Test of Resistance to } \\
\text { Change }\end{array}$} \\
\hline & & $\begin{array}{l}\text { Bright } \\
\text { Houselight }\end{array}$ & $\begin{array}{c}\text { Dim } \\
\text { Houselight }\end{array}$ & & \\
\hline \multirow[t]{7}{*}{6693} & 1 & - & - & 20 & Prefeeding for 5 sessions \\
\hline & 2 & - & 60 & 22 & - \\
\hline & 3 & - & 30 & 90 & - \\
\hline & 4 & - & 15 & 31 & - \\
\hline & 5 & - & 7.5 & 25 & Prefeeding for 5 sessions \\
\hline & 6 & - & 7.5 & 23 & Extinction 1 for 20 sessions \\
\hline & 7 & - & 7.5 & 22 & Extinction 2 for 17 sessions \\
\hline \multirow[t]{6}{*}{9297} & 1 & - & - & 76 & Prefeeding for 5 sessions \\
\hline & 2 & - & 60 & 24 & - \\
\hline & 3 & - & 30 & 34 & - \\
\hline & 4 & - & 15 & 68 & Prefeeding for 5 sessions \\
\hline & 5 & - & 15 & 23 & Extinction 1 for 20 sessions \\
\hline & 6 & - & 15 & 41 & Extinction 2 for 7 sessions \\
\hline \multirow[t]{7}{*}{9980} & 1 & - & - & 47 & Prefeeding for 5 sessions \\
\hline & 2 & 60 & - & 20 & - \\
\hline & 3 & 30 & - & 34 & - \\
\hline & 4 & 15 & - & 53 & Prefeeding for 5 sessions \\
\hline & 5 & 15 & - & 20 & Extinction 1 for 20 sessions \\
\hline & 6 & 15 & - & 60 & Extinction 2 for 7 sessions \\
\hline & 7 & - & - & 26 & - \\
\hline
\end{tabular}


As in Experiment 1, stable performance was disrupted by prefeeding and extinction. There were two types of extinction tests in Experiment 2, however. During the first extinction test (Condition 6, 5, and 5 for Pigeons 6693, 9297, and 9980, respectively, on Table 4), the VT food schedule was retained in one component of the multiple schedule but no food was delivered following completion of a DMTS trial in both components. During the second extinction test (Condition 7, 6, and 6 for Pigeons 6693, 9297, and 9980, respectively), the VT schedule was removed. Thus, all food delivery was discontinued. All other procedural details during the disruption tests were identical to those in Experiment 1.

\section{Results}

Figure 6 shows mean response rates $(+1 \mathrm{SD})$ during the VI initial links leading to the DMTS trial across the last five sessions of each condition. The black bars shows response rates in the component in which the duration of the VT-food schedule superimposed on the initial-link VI 60-s schedule was varied (hereafter varied component). The gray bars show response rates in the component in which no VT-food schedule was superimposed (hereafter constant component). In all pigeons, the response rates in the constant component remained relatively unchanged across conditions, whereas those in the varied component were inversely related to the duration of the VT-food schedule superimposed. 


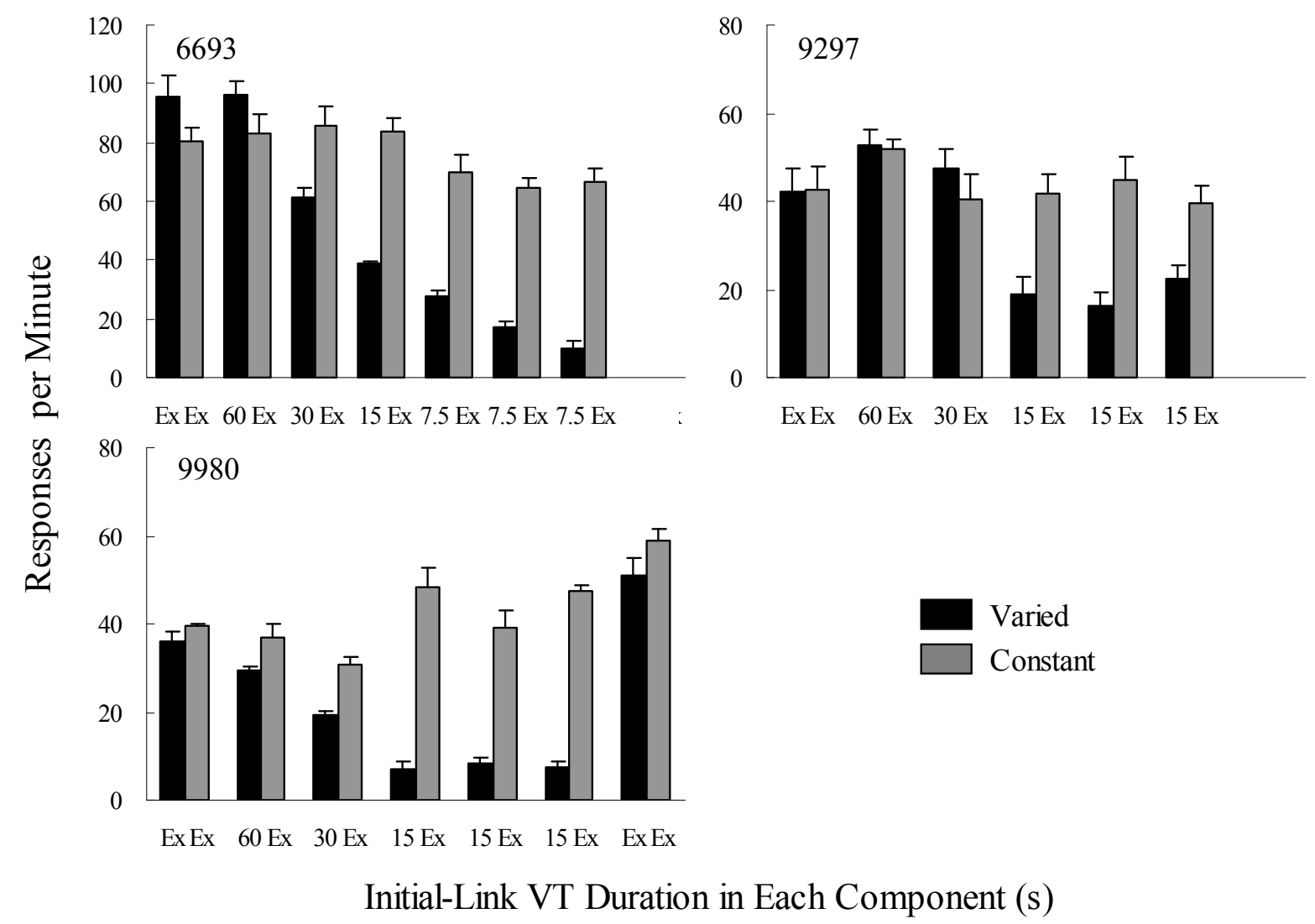

Figure 6. Mean rates of responses per minute as a function of the duration of the VT-food schedule superimposed on the initial-link VI schedules in Experiment 2. The black bars show rates of responses in the component in which various VT-food schedules were superimposed across conditions. The gray bars show rates of responses in the component in which no VT-food schedule was superimposed. The numbers below bars indicate the duration of the VT schedule arranged in each component. Error bars represent one standard deviation. "Ex" refers to extinction in which no VT-food was delivered.

The left panel of Figure 7 shows mean $\log d(+1 \mathrm{SD})$ across the last five sessions of each condition. As with Figure 6, the black and gray bars show $\log d$ in the varied and constant components, respectively. Comparisons across conditions indicate that, in all pigeons, $\log d$ in the varied component decreased when the VT-food schedule became richer. On the other hand, $\log d$ in the constant component slightly increased although there was no change in the constant component. As shown on the right panel of Figure 7, this contrast effect is more evident when 
$\log d$ is expressed as a proportion of $\log d$ of the first condition in which no VT-food schedule was superimposed in both components.
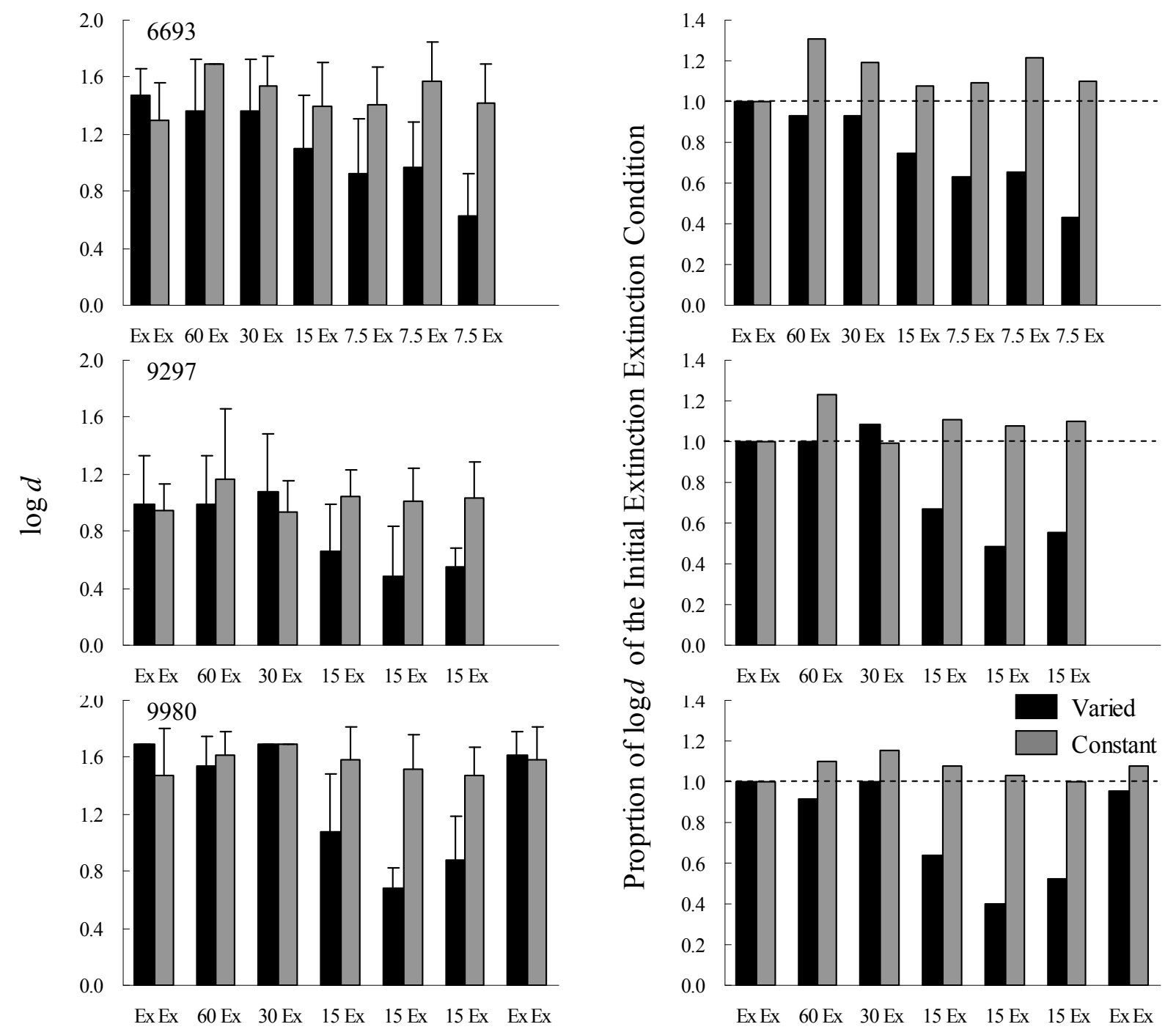

Initial-Link VT Duration in Each Component (s)

Figure 7. Mean $\log d$ (left panel) and $\log d$ expressed as a proportion of the first condition with no VT-food schedule superimposed in both components (right panel) as a function of the duration of the VT-food schedule superimposed in Experiment 2. The black bars show log $d$ in the component in which various VT-food schedules were superimposed. The gray bars show log $d$ in the component in which no VT-food schedule was superimposed. The numbers below bars indicate the duration of the VT schedule in effect. Error bars represent one standard deviation. "Ex" refers to extinction in which no VT-food was delivered. 
Figure 8 shows mean choice proportion (+ 1 SD) during the probes across the last five sessions of each condition. Pigeons 9297 and 9980 allocated more responses to the alternative leading to the sample stimuli correlated with greater reduction in delay to food reinforcement when the superimposed VT-food schedule became rich (e.g., VT $15 \mathrm{~s}$ ). As the superimposed food was expected to lower the conditioned reinforcing value of the sample stimuli in the varied component (cf. Equation 1), the results indicate that the value of the sample stimuli was higher in the constant component without the superimposed food. An exception was Pigeon 6693. This pigeon showed consistent side bias throughout the experiment and the choice proportion was unaffected by the superimposed food.

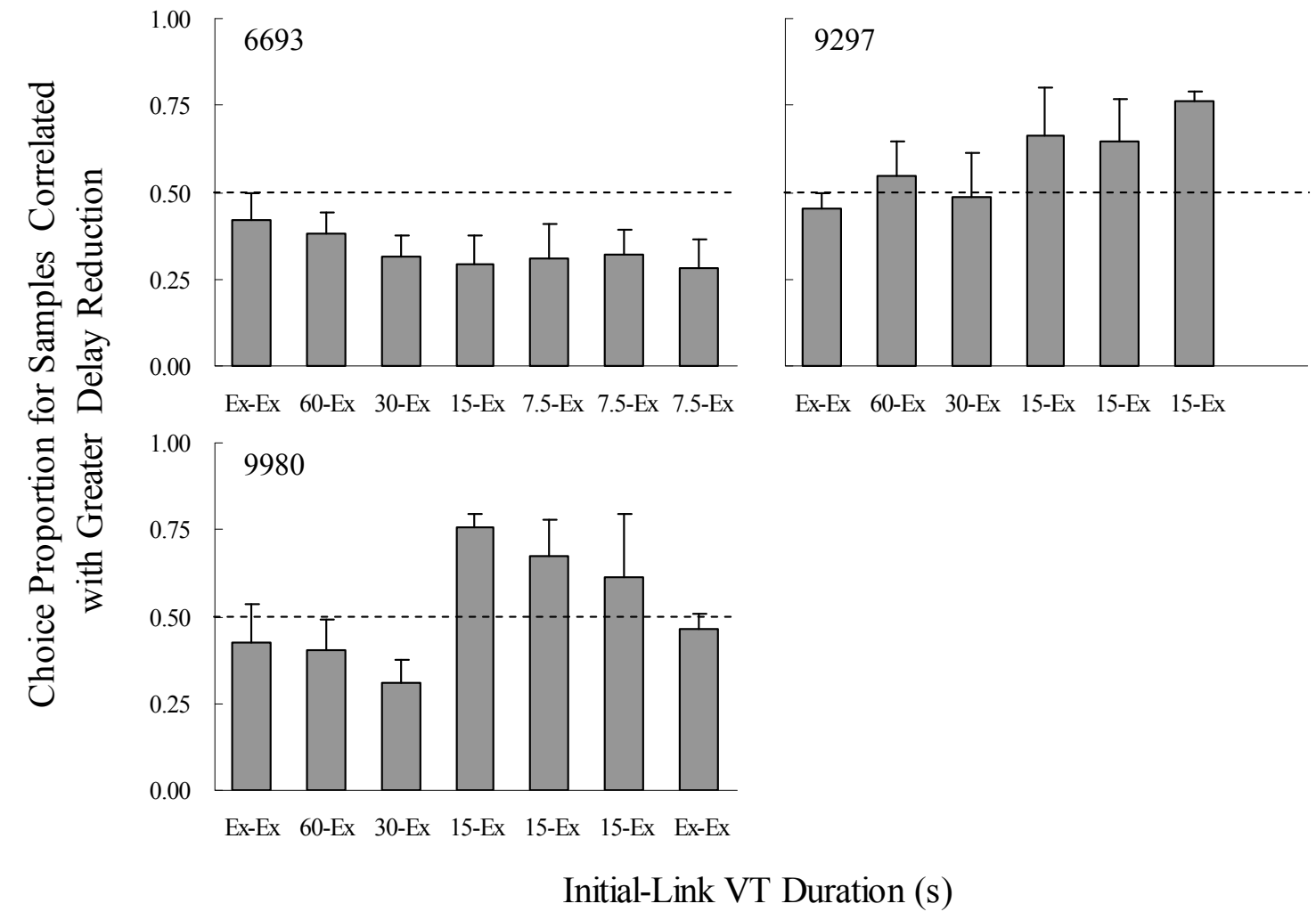

Figure 8. Mean choice proportion for sample stimuli correlated with greater reduction in delay to reinforcement during probes as a function of each experimental condition in Experiment 2. The numbers and abbreviations placed to the left and right of a hyphen below gray bars indicate the duration of the VT-food schedule superimposed in the varied and constant components, respectively. Error bars represent one standard deviation. "Ex" refers to extinction in which no VT-food was delivered. 
Figure 9 shows response rates during the tests of resistance to change. The response rates during the VI initial links are expressed as a log proportion of the mean response rate of the last five baseline sessions immediately prior to each resistance to change test. As on Figure 4, the lowest value was set to -2.0. On this figure and Figure 10, the first and second extinction tests are designated as "EX1" and "EX2," respectively. During the first extinction test, the VT-food delivery was retained but no food was delivered on completion of the DMTS trial, whereas during the second extinction test, all food delivery was discontinued.

The first row of Figure 9 shows the results from the prefeeding test following the baseline sessions in which the no VT-food schedule was superimposed. In all pigeons, responding in the two components decreased at almost equal rates as test sessions proceeded. There was no systematic difference in resistance to change between the components. The second through fourth rows show the results from the prefeeding and the first and second extinction tests following the baseline sessions in which the VT-food schedule was superimposed in one of the components. With the results of all tests being combined, in six out of the nine cases, resistance to change was greater in the varied component with the VT food than in the constant component without the VT food. The results of the first extinction test, however, show somewhat unusual pattern of changes. As shown in the third row of the figure, all pigeons continued responding in both components even at the end of 20 extinction sessions. This is in contrast to the results of the second extinction test (the fourth column). In this test, responding during the initial links was completely extinguished in all pigeons. 

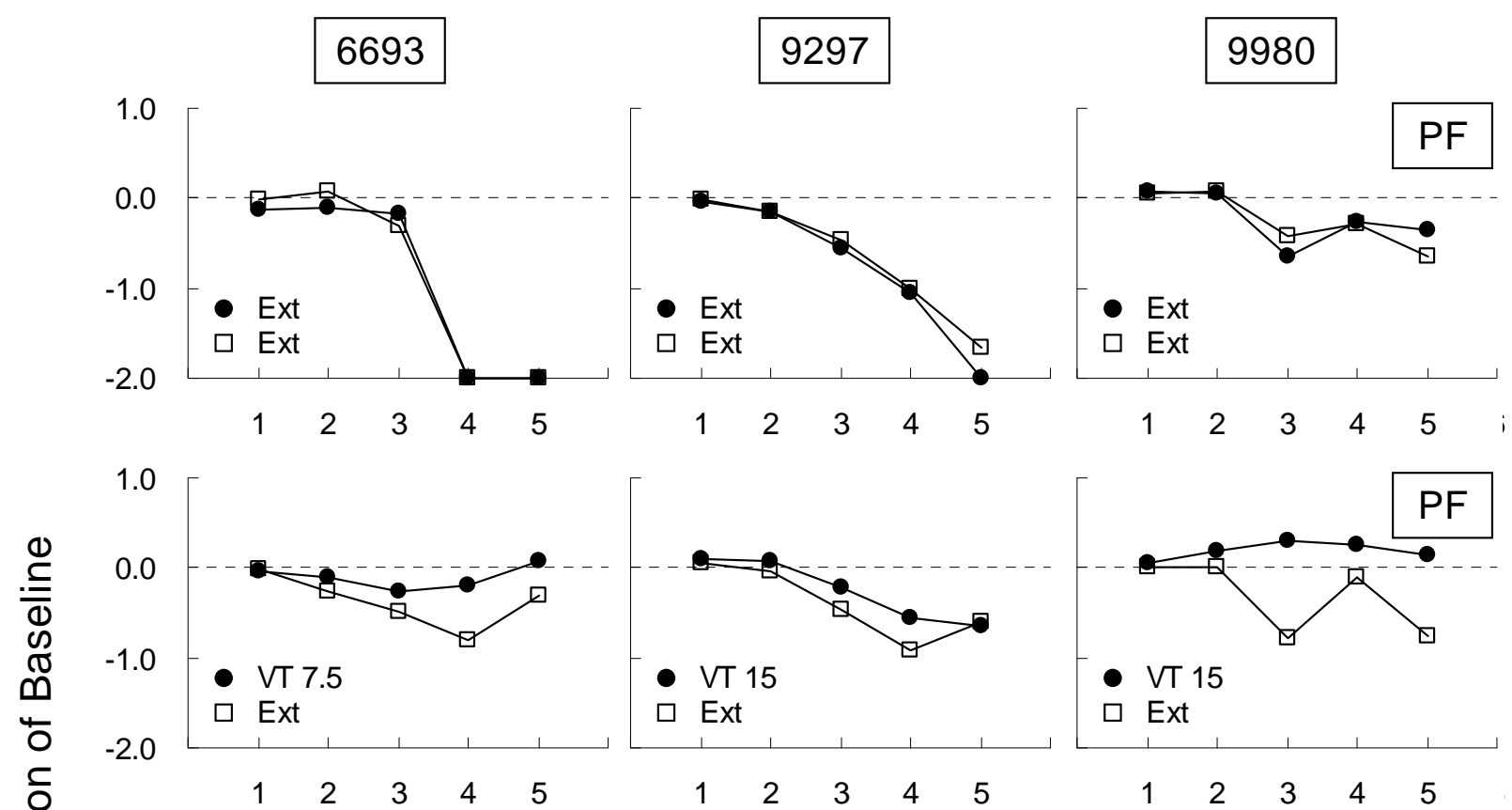

- VT 15

$\square$ Ext
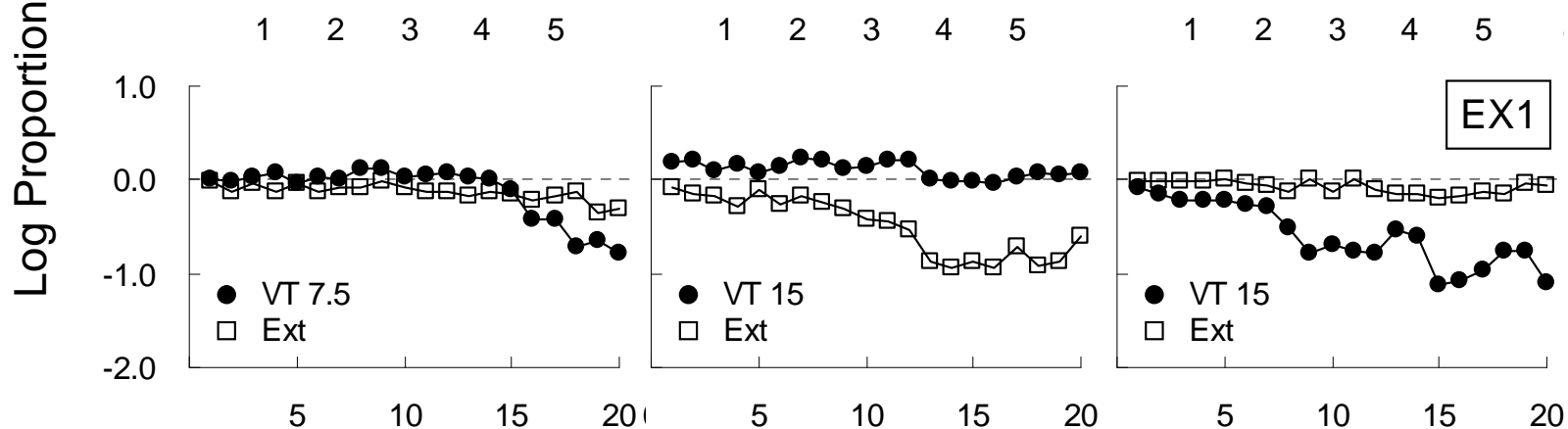

Ext
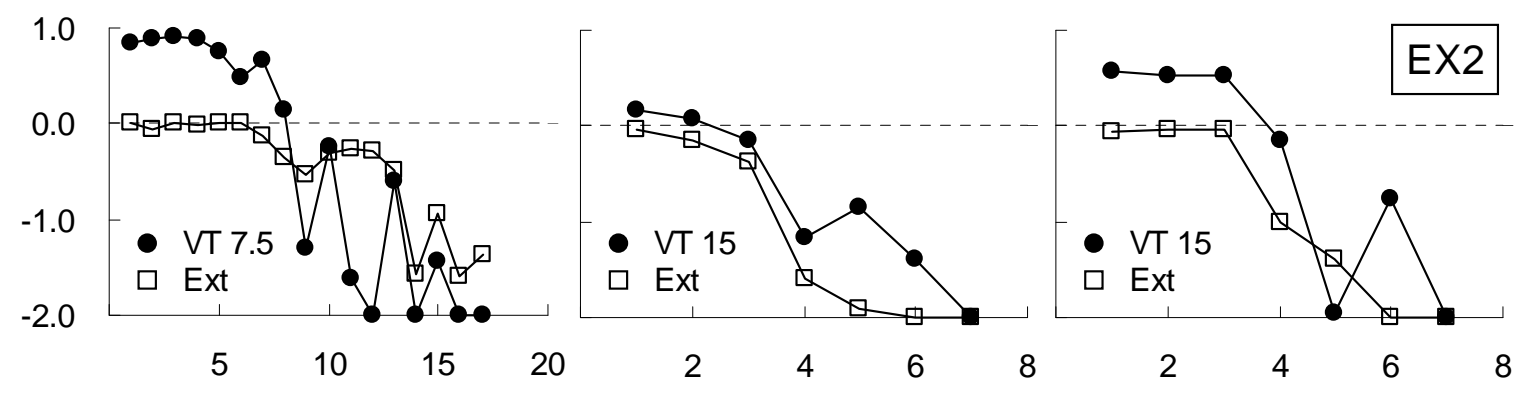

Successive Test Sessions

Figure 9. Response rates during the VI initial links expressed as a log proportion of the mean of the last five baseline sessions immediately prior to each resistance to change test as a function of successive test sessions in Experiment 2. Closed circles and open squares represent log proportion of response rates in the varied and constant components, respectively. "PF" refers to the prefeeding test. "EX1" and "EX2" refer to extinction tests with and without superimposed VT food, respectively. 
Figure 10 shows DMTS accuracy during the tests of resistance to change. $\log d$ is expressed as a log proportion of the mean of the last five baseline sessions over a moving window of three blocks of eight successive DMTS trials. The following remained the same as Figure 5 in Experiment 1: (a) one data point represents 24 DMTS trials; (b) only trials in which the pigeon pecked the comparison stimulus are included for analysis; (c) if a block does not contain at least six trials (out of eight trials), such a block was excluded for analysis; (d) the lowest value was set to -1.5. Mean numbers of trials excluded from each component of each test were 1.8, 0.8, and 1.5 for Pigeons 6693, 9297, and 9980, respectively.

The first row of Figure 10 shows the results from the prefeeding test following the baseline sessions in which no VT-food was superimposed. In Pigeon 6693 DMTS accuracy was not deteriorated at all. In Pigeon 9297, the deterioration was somewhat greater in one component than in the other, although no VT food was superimposed in both components. In Pigeon 9980, the deterioration was not systematically different between the components. The second through fourth rows show the results from the second prefeeding and the first and second extinction tests following the baseline sessions in which the VT-food schedule was superimposed in one of the components. With the results of the second prefeeding test (the second row) and the second extinction test (the fourth row) being combined, in four out of the six cases, DMTS accuracy deteriorated at slower rates in the varied component with the VT food than in the constant component without the VT food. That is, resistance to change of DMTS accuracy was greater when the VT food was superimposed. On the other hand, during the first extinction test (the third row), all pigeons showed greater resistance to change in the constant component in which no VT food was superimposed. As with the resistance to change of response rates on Figure 9, however, the results of this test show somewhat unusual patterns of changes. First, particularly in Pigeons 


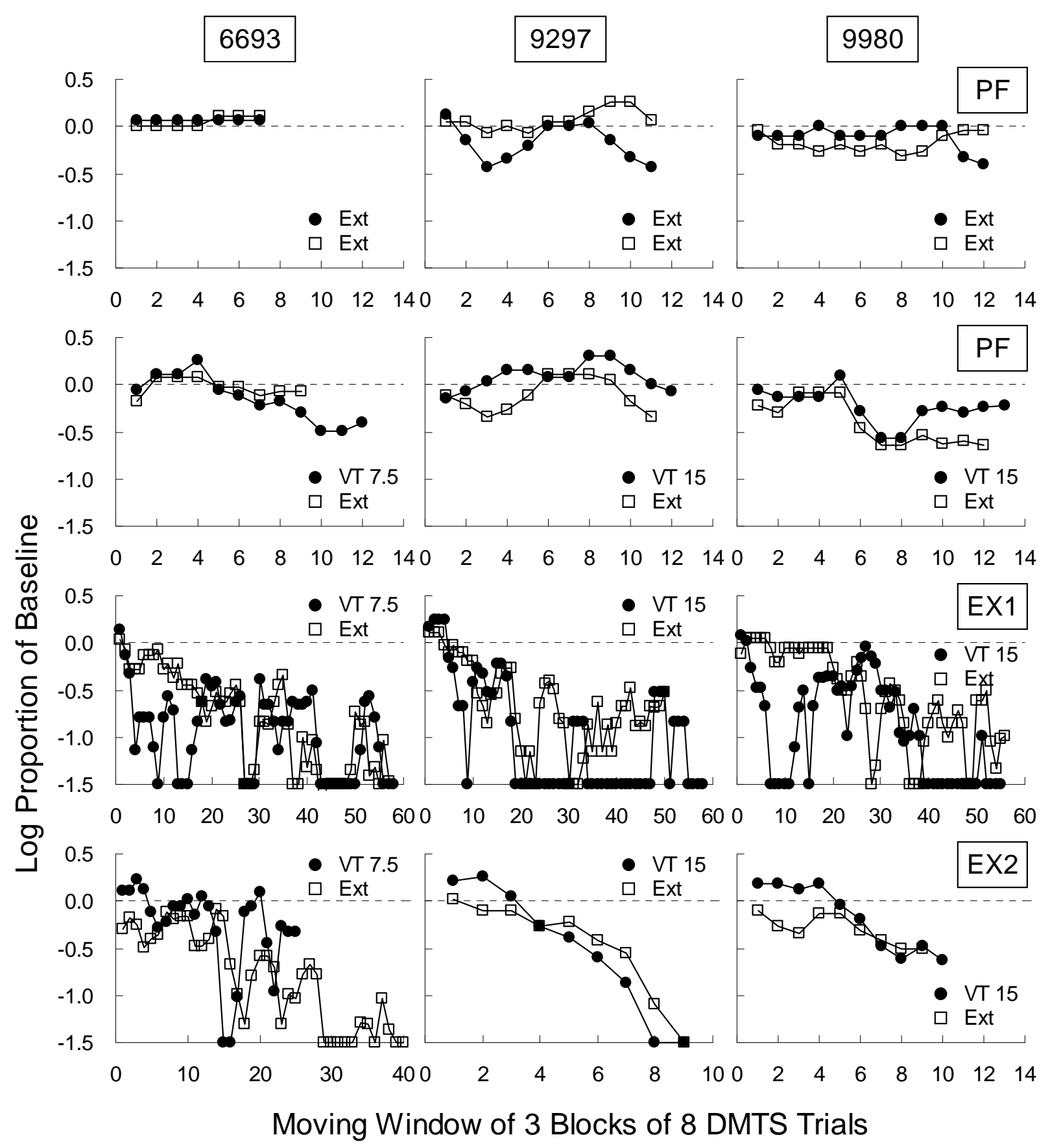

Figure 10. $\log d$ expressed as a $\log$ proportion of the mean of the last five baseline sessions immediately prior to each resistance to change test as a function of a moving window of three blocks of eight DMTS trials in Experiment 2. Closed circles and open squares represent log proportion of $\log d$ in the varied and constant components, respectively. "PF" refers to the prefeeding test. "EX1" and "EX2" refer to extinction tests with and without superimposed VT food, respectively. 
6693 and 9980, DMTS accuracy in the varied component deteriorated rapidly, relative to the rate at which DMTS accuracy deteriorated in the varied component during the second extinction test. Second, all pigeons continued responding on the DMTS trials in both components throughout the extinction test, despite the fact that no food was delivered on completion of a DMTS trial. The percent of DMTS trials completed during the entire 20 extinction sessions was 99.3, 93.6, and 95.7 for Pigeons 6693, 9297, and 9980, respectively.

\section{Discussion}

In Experiment 2, a VT-food schedule was superimposed on the initial-link VI schedule leading to DMTS trials in one of the components to alter the conditioned reinforcing value of the sample stimuli. During baseline, both response rates and DMTS accuracy in the varied component were inversely related to the duration the VT schedule imposed: the richer the VT schedule, the lower both response rates and DMTS accuracy. During the tests of resistance to change, stable performance was disrupted by prefeeding and two types of extinction. Results from the prefeeding test and the extinction test in which all food was discontinued show that in two out of the three pigeons, both response rates and DMTS accuracy were more resistant to change in the component with the VT-food schedule superimposed.

The finding that response-independent food delivered during the initial links decreased (baseline) DMTS accuracy is consistent with previous studies (e.g., Spetch, 1985; Wilkie, 1984). Wilkie, for example, demonstrated that DMTS accuracy was disrupted by response-independent food delivered during the ITI. With respect to the mechanisms underlying such disruption, it may be possible that the VT food disrupted performance by changing deprivation levels. As shown on Figure 7, however, the decrease in DMTS accuracy was observed only in the component in which VT food was delivered. If the decrease in DMTS accuracy had been due to change in 
deprivation levels, DMTS accuracy in the other component without VT food would have been disrupted as well. Therefore, the decrease in DMTS accuracy should be attributed to the change in the conditioned reinforcing value of the sample stimuli.

As in Experiment 1, the covariation between baseline DMTS accuracy and the value of the conditioned reinforcing value of the sample stimuli, as measured by choice proportion during the probes, was observed in two of the three pigeons. Of particular significance is the fact that such a covariation was replicated in a different procedure. Superimposing VT food altered the conditioned reinforcing value of the sample stimuli without changing between-trial spacing. This eliminated the possibility that higher DMTS accuracy observed in Experiment 1 was due to mere trial-spacing. Rather, the higher accuracy should be attributed to the higher conditioned reinforcing value of the sample stimuli. This finding further supports the delay-reduction analysis of DMTS accuracy (Wixted, 1989). According to this analysis, DMTS accuracy is a function of the value of the sample stimuli as a conditioned reinforcer, as determined by relative reduction in delay to food reinforcement.

With respect to the results from the prefeeding and the second extinction tests, in two of the three pigeons, resistance to change of DMTS accuracy was greater in the varied component with the VT-food schedule superimposed. This is consistent with previous studies (e.g., Nevin et al., 2003, 2009; Odum et al., 2005). In accord with behavioral momentum theory (e.g., Nevin, 1992; Nevin \& Grace, 2000), both present and previous studies showed that resistance to change of DMTS accuracy was greater in the component with higher primary reinforcement rate.

The results of the first extinction test, on the other hand, need to be interpreted carefully. During this test, the VT-food schedule was retained but no food was delivered on completion of a DMTS trial. As shown in the third column of Figure 9, the response rates during the initial link 
were not extinguished even at the end of the 20 extinction sessions. In addition, while not on the figures, all pigeons continued responding on the DMTS trial in both components throughout the extinction test. These observations raise some doubt that the behavior was under extinction. Indeed, there are some potential sources of reinforcement that might have maintained responding. First, responding during the initial link in the varied component might have been adventitiously reinforced due to the superimposed food. Second, responding during the initial link might have been maintained by the presentation of the sample stimuli as a conditioned reinforcer.

Particularly, since the value of the sample stimuli was higher in the constant component, the stimuli might have maintained responding longer than the sample stimuli in the varied component. Previous research supports this possibility. Using an observing-response procedure, for example, Shahan and Jimenez-Gomez (2006) similarly found that observing response during extinction was maintained when they discontinued primary reinforcement but not conditioned reinforcement. Particularly, they found that responding was maintained longer in the component within which the value of the conditioned reinforcement was higher. Finally, given the highly rich VT-food schedule (e.g., VT 7.5 s) retained during the initial link of the varied component, any responding occurred outside of the initial link might have been negatively reinforced by escaping from the situation in which no food was delivered (cf. Dinsmoor, Lee, \& Brown, 1986). What remains unclear, however, is the reason why DMTS accuracy abruptly decreased only in the component in which the VT food was delivered. This abrupt change is inconsistent with extinction in that extinction operates relatively gradually. Perhaps, a sharp contrast in reinforcement density from a heavily rich VT schedule (e.g., VT 7.5 or $15 \mathrm{~s}$ ) during the initial link to the very lean schedule (extinction) on the DMTS trial might have disrupted DMTS 
accuracy in some ways (cf. Perone \& Courtney, 1992). Further study is needed to pinpoint the ongoing behavioral process(es).

\section{General Discussion}

\section{Summary of Findings}

The primary purpose of the present study was to investigate the role played by the conditioned reinforcing value of the sample stimulus on resistance to change of DMTS accuracy. The multiple chain VI-DMTS chain VI-DMTS paradigm was used in both experiments. The multiple-schedule components differed in terms of parameters that theoretically alter the conditioned reinforcing value of the sample stimulus. In Experiment 1, the putative value of the sample stimulus in one component was altered by increasing the length of the initial-link VI schedule leading to the DMTS trial. In Experiment 2, the putative value was altered by superimposing response-independent food deliveries during the initial link. The conditioned reinforcing value of the sample stimulus was assessed on occasional probes independently of matching accuracy. The results of the probes indicate that the manipulation impacted the conditioned reinforcing value of the sample stimuli. Despite this fact, however, resistance to change of DMTS accuracy was not systematically related to the value of the sample stimuli in both experiments. The conditioned reinforcing value of the sample stimuli does not play an important role in determining resistance to change of DMTS accuracy.

There was suggestive evidence, on the other hand, that resistance to change of DMTS accuracy was systematically related to rates of primary reinforcement. In Experiment 1, one pigeon showed greater resistance to change in the component with a shorter VI schedule, whereas the other three pigeons showed no differential resistance between components. In Experiment 2, two out of three pigeons showed greater resistance to change in the component 
with the VT-food schedule superimposed. The rate of primary reinforcement was higher in the component with the shorter VI schedule in Experiment 1 and in the component with the VT-food schedule in Experiment 2. Although only suggestive, these results are in general agreement with the results of Nevin and his colleagues (e.g., Nevin et al., 2003, 2009; Odum et al., 2005), demonstrating that resistance to change of DMTS accuracy is higher in the component with the higher reinforcement probability. In accord with behavioral momentum theory, resistance to change of matching accuracy should be directly related to rate of primary reinforcement.

Recall that the present study was designed to examine the possibility of reconciling the discrepancy between the results of Schaal et al. (2000) and Nevin et al. (2003). Schaal et al. found greater resistance to change of DMTS accuracy in the component with the longer VI schedule leading to the DMTS trial. These results are inconsistent with behavioral momentum theory in that resistance to change was greater in the component with lower primary reinforcement rate. On the other hand, Nevin et al. found greater resistance to change in the component with higher probability of reinforcement for correct matches. The results are consistent with behavioral momentum theory in that rate of primary reinforcement was higher in the component with higher reinforcement probability. According to the delay-reduction analysis of DMTS accuracy, however, there was no discrepancy between the results of Schaal et al. and Nevin et al. In both studies, the conditioned reinforcing value of the sample stimuli was higher in the component in which greater resistance to change was observed.

As mentioned earlier, however, the results of the present study showed that the conditioned reinforcing value of the sample stimuli does not play an important role in determining resistance to change of DMTS accuracy. Therefore, the discrepancy between two studies cannot be reconciled in terms of the delay-reduction analysis of DMTS accuracy. 
Perhaps, the discrepancy between the results of Schaal et al. (2000) and Nevin et al. (2003) should be attributed to the different types of disruptors employed in both studies. Recall that Schaal et al. used increasing delay between sample and comparison stimuli, whereas Nevin et al. used commonly used disruptors such as prefeeding and extinction. Experiment 1 of the present study systematically replicated Schaal et al.'s study with prefeeding and extinction and found that none of the pigeons showed greater resistance to change of DMTS accuracy in the component with the longer VI schedule leading to the DMTS trial. The results are in sharp contrast to those of Schaal et al., in that all of their pigeons showed greater resistance in the component with the longer VI schedule. Therefore, it may be that the effects of increasing delay as an internal disruptor are independent of reinforcement conditions prior to its introduction (cf. Harper \& McLean, 1992) and that the different types of disruptors (internal versus external) used in both studies could account for the discrepancy between the results of the two studies.

\section{Limitations of the Present Study}

There are at least two limitations in the present study. First, the probes to assess the conditioned reinforcing value of the sample stimuli might have not been sensitive enough. This is shown by the fact that for some pigeons choice proportion for the sample stimuli correlated with greater reduction in delay to reinforcement was not systematically affected by the VI schedule leading to DMTS trials (Experiment 1; shown on Figure 3) or the superimposed VT schedule (Experiment 2; shown on Figure 8). For example, Pigeon 6693 in Experiment 2 consistently pecked the right key more frequently than the left key, regardless of the VT food schedule in effect. One possible reason for this insensitivity is that the sample stimuli presented during the terminal link of the probes were compound stimuli consisting of red or green light on the center key under the bright or dim houselight. It may be that such compound stimuli as a 
terminal link-stimulus exert only weak control over the response allocation during the initial link. Alternatively, generalization decrement between the VI-DMTS trials and the probes may account for the insensitivity. Recall that the value of the sample stimuli as a conditioned reinforcer was altered in the VI-DMTS trials and then the value was assessed in the probes. Although the sample stimuli in VI-DMTS trials were exactly the same as the terminal-link stimuli in the probes, the context in which such stimuli were presented was different. This difference might have blocked generalization between the two contexts that is necessary for the conditioned reinforcing value of the sample stimuli to be reflected on choice proportion during the initial links of the probes. To isolate the variable(s) responsible for the insensitivity of the probe procedure, future research should address these issues. Instead of using compound stimuli, for example, each component of the multiple schedule should employ a unique set of stimuli for samples and comparisons. To increase the similarity between the VI-DMTS trials and the probes, on the other hand, the terminal link of the probes may also compose of a DMTS trial.

Another limitation of the present study is that the failure to find robust and consistent difference in resistance to change of DMTS accuracy might have been due to the very fact that the conditioned reinforcing value of the sample stimuli and rate of primary reinforcement were placed in opposition within a component. It might have been the case that the two variables were equally powerful and their effects on resistance to change of DMTS accuracy might have been cancelled out. In Experiment 1, for example, the conditioned reinforcing value of the sample stimuli was higher but the primary rate of reinforce was lower in the component in which the length of the initial-link VI schedule was $125 \mathrm{~s}$ than in the component in which the length was 20 s. If both variables contributed to resistance to change, there is no surprise that no differential resistance to change was observed. Perhaps the effectiveness of these variables differs across 
subjects and this could account for the individual differences observed in the present study. Future study should examine relative contribution of the conditioned reinforcing value of the sample stimuli and rates of primary reinforcement on resistance to change of DMTS accuracy by keeping one variable constant while manipulating the other.

\section{Extension of Resistance to Change Literature}

The present results extend previous research on resistance to change in two ways. First, with respect to resistance to change of matching accuracy, the results of Experiment 2 add to the generality of behavioral momentum theory by providing strong evidence that resistance to change of matching accuracy is an orderly function of rate of primary reinforcement.

Behavioral momentum theory states that resistance to change solely is determined by rate of primary reinforcement in the stimulus context, whether reinforcement is response-dependent or response-independent (e.g., Nevin \& Grace, 2000). In Experiment 2, greater resistance to change was observed in the component with the VT-food schedule superimposed on the VI schedule leading to the DMTS trial. This is the first demonstration that resistance to change of DMTS accuracy was enhanced by alternative source of reinforcement delivered in the same stimulus context but outside of the DMTS trial. Indeed, all previous studies on resistance to change of DMTS accuracy that are in accord with behavioral momentum theory arranged different probability of reinforcement between the components (e.g., Nevin et al., 2003). Therefore, the similar finding obtained in the present study with the different procedure of manipulating rate of primary reinforcement is of great significance in terms of increasing the generality of previous findings.

It is worth noting that the procedures and the results of Experiment 2 are highly similar to those of Nevin et al. (1990). They examined relation between alternative source of reinforcement 
and resistance to change of free-operant responding (rather than DMTS accuracy). In their Experiment 1, pigeons were trained on a two-component multiple schedule with equal VI 60-s schedules. A VT-food schedule was superimposed on the VI schedule in one component. Stable performance then was disrupted by prefeeding and extinction. Whereas rate of responding during baseline was lower in the component with the superimposed VT food, resistance to change was greater in that component. Nevin et al. concluded whereas the response-independent food degrades the operant response-reinforcer contingency that governs baseline rate of responding, it enhances the Pavlovian stimulus-reinforcer contingency that governs resistance to change. In the present study, DMTS accuracy during baseline was lower in the component with the VT food, whereas resistance to change was greater in that component. This similarity may suggest that the same behavioral process operate between the two. As with free-operant responding, baseline matching accuracy and resistance to change should be governed by the operant and Pavlovian contingencies, respectively.

Second, with respect to resistance to change of behavior maintained by conditioned reinforcement, the results of both of the present experiments are consistent with those of Shahan and Podlesnik (2008). Using a multiple schedule of observing-response procedures, Shahan and Podlesnik investigated the relation between the conditioned reinforcing value of the stimulus positively correlated with a VI food schedule $(\mathrm{S}+)$ and resistance to change of the observing responses maintained by the $\mathrm{S}+$. Two components differed in terms of parameters that altered the conditioned reinforcing value of the $\mathrm{S}+$, as determined by relative reduction in delay to food reinforcement. In their Experiment 1, response-independent food deliveries were superimposed in one component. The superimposed food decreased the conditioned reinforcing value of S+but increased rate of primary reinforcement. In their Experiment 2, the probability of the VI schedule 
periods relative to extinction periods was increased in one component. This manipulation decreased the value of the $\mathrm{S}+$ while increasing the primary reinforcement rate. In accord with the results of the present study, Shahan and Podlesnik found that the value of the S+ affected baseline rate of observing responses but not resistance to change.

The present results extend those of Shahan and Podlesnik (2008) to resistance to change of DMTS accuracy. In essence, both studies demonstrate that the value of the conditioned reinforcer affects baseline performance but not resistance to change. As Shahan and Podlesnik $(2005,2008)$ argued, the value of a conditioned reinforcer may affect baseline performance through a mechanism other than response strengthening as measured by resistance to change. In general, the value of a conditioned reinforcer does not increase the strength of the very behavior that the conditioned reinforcer follows. With respect to matching accuracy in particular, the value of the sample stimulus as a conditioned reinforcer may not increase the strength of the control that the sample stimulus exerts, also as measured by resistance to change. Rather than response-strengthening effects, the value of a (putative) conditioned reinforcer may have its effect on behavior by signaling the occurrence of primary reinforcers. Indeed, the hypothesis that the function of a (putative) conditioned reinforcer is discriminative rather than responsestrengthening has received some empirical support with different procedures of arranging conditioned reinforcement (e.g., concurrent-chain procedure, Schuster, 1969; brief-stimulus pairing procedure, Davison \& Baum, 2006). This line of arguments leads to the conjecture that primary and conditioned reinforcers are not synonymous in their effects on behavior—only primary reinforcers strengthen behavior that they follow.

Alternatively, the failure to find the evidence that a conditioned reinforcer strengthens behavior might have been due to the fact that both conditioned reinforcement and resistance to 
change are based on Pavlovian conditioning and that a second-order conditioning is required if resistance to change is affected by a conditioned reinforcer (Shahan \& Podlesnik, 2005, 2008). In the case of the present study, for example, the association between a sample stimulus and a food reinforcer is the first-order conditioned stimulus-unconditioned stimulus association $\left(\mathrm{CS}_{1}\right.$-US association). Then, the association between the houselight as a stimulus context and a sample stimulus as a conditioned reinforcer is the second order conditioning $\left(\mathrm{CS}_{2}-\mathrm{CS}_{1}\right.$ association). Note that the first- and second-order conditioning corresponds to delay reduction and resistance to change processes, respectively. Therefore, the lack of effects of the conditioned reinforcing value of the sample stimuli on resistance to change of DMTS accuracy may reflect the fact that the second-order conditioning $\left(\mathrm{CS}_{2}-\mathrm{CS}_{1}-\mathrm{US}\right.$ association) is required for the conditioned reinforcer to impact resistance to change. Indeed, Williams and Dunn (1991) argued that the results of Schuster's (1969) study, showing that a conditioned reinforcer did not exert responsestrengthening effect, might have been due to lack of second-order conditioning.

In conclusion, the mechanism underlying the failure to find the evidence that a conditioned reinforcer strengthens behavior is still unclear. Further research is needed for better understanding of such mechanism. Meanwhile, the results of the present study should be important in that they demonstrated that the finding of Shahan and Podlesnik (2008) was replicated in a DMTS paradigm.

Value of a Conditioned Reinforcer and Baseline DMTS Performance

Regardless of the mechanism underlying the finding that the conditioned reinforcing value of the sample stimuli only affects baseline DMTS accuracy, the finding that the value does affect baseline DMTS accuracy is of significance for its own right. Several previous studies have found that baseline DMTS accuracy was affected by the various reinforcement variables, such as 
magnitude, probability, or delay. For example, using the multiple chain VI-DMTS chain VIDMTS paradigm, Nevin and his colleagues (Nevin et al., 2003; Odum et al., 2005) found that matching accuracy was higher in the component with higher probability of reinforcement for correct matches than in the component with lower probability. Brown and White (2005b) also obtained a similar result using a standard DMTS procedure. The results of these studies led Nevin et al. to conclude that rate of primary reinforcement affects DMTS accuracy in the same way as it affects free-operant responding: the higher reinforcement rate, the higher the DMTS accuracy (and the higher the response rate).

It is important to note, however, that arranging a higher probability of reinforcement in one component also increases the value of the sample stimuli in that component, as determined by relative reduction in delay to food reinforcement. Therefore, if DMTS accuracy is higher in the component in which higher probability of primary reinforcement is arranged, such results can be accounted for both by primary reinforcement rate and by conditioned reinforcing value of the sample stimulus.

Recall that in the present study increasing the length of the initial-link VI schedule leading to the DMTS trial (Experiment 1) and superimposing a VT-food schedule (Experiment 2) alters rate of primary reinforcement and the conditioned reinforcing value of the sample stimulus in opposite directions. For example, when VI 20-s and 125-s schedules are arranged in the two components, the conditioned reinforcing value of the sample stimuli is higher but rate of primary reinforcement is lower in the component with a VI 125 s. As shown on Figures 2 and 7, DMTS accuracy was higher in the component with a longer VI schedule (Experiment 1) and without the superimposed VT schedule (Experiment 2). These results suggest that the conditioned reinforcing value of the sample stimuli, rather than rate of primary reinforcement, is 
a dominant variable that determines baseline DMTS accuracy. Therefore, higher DMTS accuracy in the component with higher primary reinforcement rate reported in the previous studies should be attributed to the higher conditioned reinforcing value of the sample stimuli. While the value of a conditioned reinforcer is affected by the rate of primary reinforcement in a Pavlovian stimulus-reinforcer contingency, it is the rate of primary reinforcement relative to overall reinforcement rate in a stimulus context, rather than absolute rate of primary reinforcement, that determines the conditioned reinforcing value of the sample stimuli. The value, in turn, determines matching accuracy.

The notion that the conditioned reinforcing value of the sample stimuli determines matching accuracy is by no mean new. Both theoretical (e.g., Wixted, 1989) and empirical (e.g., Roberts \& Kraemer, 1982) support may be found in the literature. Particularly, Schaal et al. (2000) employed the almost same procedure as that of Experiment 1 of the present study. In both studies, when the conditioned reinforcing value of the sample stimuli and the rate of primary reinforcement were placed in opposition, DMTS accuracy was governed by the conditioned reinforcing value of the sample stimuli. In spite of this evidence from the previous studies, however, the results of the present study made two unique contributions to the literature.

First, the conditioned reinforcing value of the sample stimuli was independently assessed outside of the DMTS context. Rather than merely assuming that the conditioned reinforcing value of the sample stimuli is altered by arranging differential reduction in delay to food reinforcement, the value was actually measured during the probes. As shown on Figures 3 and 8 , most pigeons showed preference toward the alternative correlated with greater reduction in delay to food reinforcement. This suggest that increase in the length of the VI schedule (Experiment 1) and superimposing a VT-food schedule (Experiment 2) actually affected the value of the sample 
stimuli as conditioned reinforcers. As shown on Figure 2 and 7, such a change in the value of the sample stimuli is positively correlated with a change in DMTS accuracy. This covariation is consistent with the notion that the conditioned reinforcing value of sample stimuli determines DMTS accuracy.

Second, the results of Experiment 2 are important in that the value of the sample stimuli was altered in a novel way. With the exception of Hartl et al. (1996), who altered the value by changing the duration of the sample-stimulus presentation, all other previous studies that investigated the relation between the conditioned reinforcing value of the sample stimuli and DMTS accuracy altered the value by changing the interval between trials (e.g., Roberts, \& Kraemer, 1982). As mentioned in the General Introduction, increase in between-trial spacing is inevitably confounded by attenuation of proactive interference. By altering the value with superimposed food, the results of Experiment 2 excluded the possibility that the results of the previous studies can be due to trial-spacing effects. Taken together with the study by Hartl et al., the present study increases the generality of the previous finding by showing that the conditioned reinforcing value of the sample stimuli, rather than rate of primary reinforcement, determines DMTS accuracy.

\section{Value of a Conditioned Reinforcer and Behavioral Contrast}

Behavioral contrast (e.g., Reynolds, 1961) refers to an inverse relation between response rate in one component of a multiple schedule and reinforcement rate in the other component. Positive contrast refers to increase in response rate in one component when reinforcement rate in the other component decreases, whereas negative contrast refers to decrease in response rate in one component when reinforcement rate in the other component increases. Behavioral contrast is 
a robust phenomenon. It has been observed in several species in different procedures (see Williams, 1983, 2002, for review).

In the present study, both positive and negative contrasts were observed in DMTS accuracy. As shown on the right column of Figure 2, DMTS accuracy in the constant component (no change in the length of the VI schedule) decreased when the length of the VI schedule in the other (varied) component was increased (negative contrast). Similarly, Figure 7 shows that DMTS accuracy in the constant component (no VT food superimposed) increased when the VTfood schedule was superimposed in the other (varied) component (positive contrast). Some pigeons (e.g., Pigeon 9980 on Figure 7) show only small increase in DMTS accuracy in some positive-contrast conditions. This is probably due to a ceiling effect-the discrimination performance was already very high and there was not much room for improvement.

The present results make two contributions to the literature on behavioral contrast. First, they extend the previous research on behavioral contrast to a procedure other than simple operant responding (see also da Silva \& Lattal, 2006; Farthing, 1975; Wilkie, 1973, for different dependent measures other than DMTS accuracy). While Nevin, Shahan, and Odum (2008, Experiment 2) also found that behavioral contrast occurred in DMTS accuracy, the results are limited because only one of the two multiple-schedule components included DMTS trials. Nevin et al. arranged a chain VI-DMTS schedule in one component throughout the experiment (constant component) and a VI 25-s schedule or extinction in the other component across conditions (varied component). Matching accuracy in the constant component was higher when extinction was arranged in the varied component than when the VI 25-s schedule was arranged. This finding certainly meets the definition of behavioral contrast. However, an alternative account in terms of the conditioned reinforcing value of sample stimuli is possible. Note that 
when extinction was arranged in the varied component, the average interreinforcement interval at a session level increased while the delay from the sample onset to food delivery remains constant. Therefore, according to Equation 1, the value of the sample stimuli as a conditioned reinforcer should increase, as in the case when the length of the VI schedule leading to the DMTS was increased. This change in the conditioned reinforcing value of the sample stimuli, in turn, could account for the change in DMTS accuracy in the constant component.

The present study, on the other hand, employed a multiple chain VI-DMTS chain VIDMS schedule. In Experiment 1, increasing the length of the VI schedule in the varied component increased DMTS accuracy in that component while it decreased DMTS accuracy in the constant component. In Experiment 2, adding a VT-food schedule in the varied component decreased DMTS accuracy in that component while it increased DMTS accuracy in the constant component. In both experiments, the change in the average inter-food interval at a session level competes with the impact of behavioral contrast. In Experiment 1, the increase in the average inter-food interval should increase the value of the sample stimuli (and therefore DMTS accuracy) in both components. In Experiment 2, the decrease in the average inter-food interval should decrease the conditioned reinforcing value of the sample stimuli (and therefore DMTS accuracy) in both components. Given the demonstration of negative and positive contrast in Experiments 1 and 2, respectively, it can be concluded that the impact of behavioral contrast itself overwhelmed the impact of the change in the average inter-food interval on DMTS accuracy. In this sense, the results of the present study are a stronger demonstration of behavioral contrast in DMTS accuracy than those of Nevin et al. (2008). This further increases the generality of behavioral contrast. 
The second possible contribution that the present results could make to the analysis of behavioral contrast is to expand the scope of behavioral contrast to the magnitude of a conditioned reinforcer — namely the value of sample stimuli as a conditioned reinforcer in the present study. A majority of the previous studies have focused on behavioral contrast produced by changes in rate of primary reinforcement (see Williams, 1983, 2002, for review). Several studies, however, attempted to produce behavioral contrast by changing the amount or duration of primary reinforcement. The results are mixed. Some were successful (e.g., Kramer \& Rilling, 1969; Weatherly, Melville, \& Swindell, 1997), whereas others were not (e.g., Shettleworth \& Nevin, 1965). It is still not clear what variable(s) may be responsible for the occurrence of behavioral contrast under the control of the magnitude of primary reinforcement.

With respect to behavioral contrast and magnitude of a conditioned reinforcer, on the other hand, there is no study, to my knowledge, that reported behavioral contrast produced by changes in the magnitude (or value) of a conditioned reinforcer. The present results suggest that behavioral contrast may occur even with the change in the value of a conditioned reinforcer. As discussed previously, in Experiment 1 the value of the sample stimuli was increased in the varied component, which resulted in the decrease in the value of the sample stimuli in the constant component. In Experiment 2 the decrease in the value of the sample stimuli in the varied component resulted in the increase in the value in the constant component. The changes in the conditioned reinforcing value of the sample stimuli, however, are only inferred from DMTS accuracy. While the results of the probes indicate relative difference in the value of the sample stimuli in both components, they do not indicate absolute difference. Therefore, while the results of the present study are suggestive of the occurrence of behavioral contrast with changes in the 
value of a conditioned reinforcer, further study is needed that employs independent assessment of the change in the value of a conditioned reinforcer in each component.

\section{Applied Significance}

As discussed in General Introduction, the knowledge derived from research on resistance to change of discrimination in general could help practitioners to make desired stimulus control more persistent as well as to make undesired stimulus control less persistent. With respect to resistance to change of conditional discrimination, in particular, the knowledge derived from basic research could inform better techniques for training appropriate behavior that is under complex stimulus control. One example of such behavior is instruction-following behavior (e.g., Zimmerman, Zimmerman, \& Russell, 1969) or compliance with requests (e.g., Nevin, 1996). In essence, both instruction-following behavior and compliance with requests involve conditional discrimination in that behavior to be reinforced is dependent upon a particular instruction or request provided. For example, a teacher reinforces a child's pointing to a red object following a request, "Point to red," but not following a request, "Point to blue." Similarly, a teacher reinforces a child's pointing to a blue object following a request "Point to blue."

Once particular instruction-following behavior is acquired by explicit training, for example, it is of practical significance to make the instructional control as persistent as possible. This requires that appropriate instruction-following behavior persists even when (a) the reinforcement contingency is not arranged outside of the training environment and (b) some challenges, such as an event that lowers reinforcer effectiveness, are posed. The results of the present study suggest that the persistence of desirable instructional control is to be determined by the rate of primary reinforcement in the training context: the higher primary reinforcement rate, the more persistent desirable instructional control. 
It is worth noting that the results of Experiment 2, that DMTS accuracy was more resistant to change in the component with VT food superimposed, suggest that even responseindependent delivery of reinforcers could make the instructional control more persistent. Indeed, this is empirically demonstrated by Bullock and Normand (2006). In their study, two typicallydeveloping children were given vocal instructions that the children were less likely comply (low$p$ instructions). Note that low- $p$ instructions are considered as a disruptive challenge posed to measure persistence of instructional control. In one condition, preferred items were delivered according to an FT schedule during the sessions in which the low- $p$ instructions were delivered. Bullock and Norman found that the children complied with the low- $p$ instructions more often when the FT schedule was in effect than when it was not. These results clearly demonstrated that persistence of instructional control is determined by rate of primary reinforcement, whether it is response-dependent or response-independent.

Caution is warranted, however. Whereas response-independent reinforcer delivery enhances persistence of instructional control outside of training context, it may also attenuate the instructional control within the training context. The results of Experiment 2 suggest that this would particularly be true when the response-independent reinforcer delivery decreases the effectiveness of an instruction as a signal for reinforcer delivery (or the conditioned reinforcing value of an instruction). Therefore, response-independent reinforcers should be delivered carefully. One way to enhance persistence of instructional control without attenuating it during training is to deliver response-independent reinforcers outside of the training context. McLaughlin and Carr (2005), for example, examined the effectiveness of an intervention package including response-independent reinforcer delivery that established the presence of caregivers as generalized conditioned reinforcer (technique often designated as rapport building). 
Although the effects cannot be attributed unambiguously to the response-independent reinforcer delivery, they found that participants with developmental disabilities responded in accord with the instructions more frequently when response-independent reinforcer was paired with the caregivers outside of the training context.

Taken together, the results of the present study would be of significance in that they demonstrated general principles underlying persistence of instructional control and provided support for the effectiveness of some techniques used in applied settings. This should be an important step to bridge the gap between basic research on resistance to change and applied research on instruction following. Future research is needed to further strengthen the bridge between the two domains.

\section{Conclusion}

The results of the present study show that there is no systematic relation between the conditioned reinforcing value of the sample stimuli and resistance to change of DMTS accuracy. Instead, there was suggestive evidence that the resistance to change is directly related to the rate of primary reinforcement, in accord with behavioral momentum theory. Therefore, the discrepancy between the results of Schaal et al. (2000) and those of Nevin et al. (2003) should be attributed to the type of disruptors used. Put in general terms, the results of the present study lead to the conclusion that when conventional disruptors such as prefeeding and extinction are used, resistance to change of DMTS accuracy is governed by the rate of primary reinforcement.

What is notable throughout the present study is the dominant role that Pavlovian processes play in determination of conditional discrimination accuracy. This is demonstrated both in baseline performance and resistance to change. Despite Skinner's (1938/1966) effort to contrast his operant paradigm to Pavlov's paradigm and his success in achieving the 
behaviorist's goals of prediction and control, both operant and Pavlovian processes interact with each other in controlling behavior. The recognition and further understanding of such an interaction would lead to the construction of a unified and comprehensive science of behavior (Dinsmoor, 1985). 


\section{References}

Brown, G. S., \& White, K. G. (2005a). The optimal correction for estimating extreme discriminability. Behavior Research Methods, 37, 436-449.

Brown, G. S. \& White, K. G. (2005b). On the effects of signaling reinforcer probability and magnitude in delayed matching to sample. Journal of the Experimental Analysis of Behavior, 83, 119-128.

Bullock, C., \& Normand, M. P. (2006). The effects of a high-probability instruction sequence and response-independent reinforcer delivery on child compliance. Journal of Applied Behavior Analysis, 39, 495-499.

Carter, D. E., \& Werner, T. J. (1978). Complex learning and information processing by pigeons: A critical analysis. Journal of the Experimental Analysis of Behavior, 29, 565-601.

Cohen, S. L., Riley, D. S., \& Weigle, P. A. (1993). Tests of behavior momentum in simple and multiple schedules with rats and pigeons. Journal of the Experimental Analysis of Behavior, 60, 255-291.

Cumming, W. W., \& Berryman, R. (1965). The complex discriminated operant: Studies of matching-to-sample and related problems. In D. I. Mostofsky (Ed.), Stimulus generalization (pp. 284-330). Stanford, CA: Stanford University Press.

Darwin, C. (1955). The expression of the emotions in man and animals. New York, Philosophical Library (Original work published 1872).

da Silva, S. P., \& Lattal, K. A. (2006). Contextual determinants of temporal control: Behavioral contrast in a free-operant psychophysical procedure. Behavioural Processes, 71, 157-163.

Davison, M., \& Baum, W. M. (2006). Do conditional reinforcers count? Journal of the Experimental Analysis of Behavior, 86, 269-283. 
Davison, M., \& Nevin, J. A. (1999). Stimuli, reinforcers, and behavior: An integration. Journal of the Experimental Analysis of Behavior, 71, 439-482.

Dinsmoor, J. A. (1985). The integrative power of the CS-US interval in other contexts. The behavioral and Brain Sciences, 8, 336-337.

Dinsmoor, J. A. (1995). Stimulus control: Part I. The Behavior Analyst, 18, 51-68.

Dinsmoor, J. A., Lee, D. M., \& Brown, M. M. (1986). Escape from serial stimuli leading to food. Journal of the Experimental Analysis of Behavior, 46, 259-279.

Dube, W. V., \& McIlvane, W. J. (2002). Reinforcer rate and stimulus control in discrimination reversal learning. The Psychological Record, 52, 405-416.

Fantino, E. (1977). Conditioned reinforcement: Choice and information. In W. K. Honig \& J. E. R. Staddon (Eds.), Handbook of operant behavior (pp. 313-339). Englewood Cliffs, NJ: Prentice Hall.

Farthing, G. W. (1975). Behavioral contrast in pigeons learning an auditory discrimination. Bulletin of the Psychonomic society, 6, 123-125.

Fleshler, M., \& Hoffman, H. S. (1962). A progression for generating variable-interval schedules. Journal of the Experimental Analysis of Behavior, 5, 529-530.

Gibbon, J. (1977). Scalar expectancy theory and Weber's law in animal timing. Psychological Review, 84, 279-325.

Grant, D. S. (1975). Proactive interference in pigeon short-term memory. Journal of Experimental Psychology: Animal Behavior Processes, 104, 207-220.

Guttman, N., \& Kalish, H. I. (1956). Discriminability and stimulus generalization. Journal of Experimental Psychology, 51, 79-88. 
Harper, D. N., \& McLean, A. P. (1992). Resistance to change and the law of effect. Journal of the Experimental Analysis of Behavior, 57, 317-337.

Harrison, J. M. (1991). Stimulus control. In I. H. Iversen \& K. A. Lattal (Eds.), Techniques in the behavioral and neural sciences: Vol. 6. Experimental analysis of behavior (Part 1, pp. 251-299). Amsterdam: Elsevier.

Hartl, J. A., Dougherty, D. H., \& Wixted, J. T. (1996). Separating the effects of trial-specific and average sample-stimulus duration in delayed matching to sample in pigeons. Journal of the Experimental Analysis of Behavior, 66, 231-242.

Hartl, J. A., \& Fantino, E. (1996). Choice as a function of reinforcement ratios in delayed matching to sample. Journal of the Experimental Analysis of Behavior, 66, 11-27.

Hautus, M. J. (1995). Corrections for extreme proportions and their biasing effects on estimated values of d'. Behavior Research Methods, Instrumentation, and Computers, 27, 46-51.

Herrnstein, R. J. (1979). Acquisition, generalization, and discrimination reversal of a natural concept. Journal of Experimental Psychology: Animal Behavior Processes, 5, 116-129.

Hull, C. L. (1943). Principles of behavior. New York: Appleton-Century-Crofts.

Keller, F. S., \& Schoenfeld, W. N. (1950). Principles of psychology. New York: AppletonCentury-Crofts.

Kramer, T. J., \& Rilling, M. (1969). Effects of lowering the magnitude of reinforcement on the response rate from a baseline during a successive discrimination. Psychonomic Science, $16,249-250$.

Mackay, H. A. (1991). Conditional stimulus control. In I. H. Iversen \& K. A. Lattal (Eds.), Techniques in the behavioral and neural sciences: Vol. 6. Experimental analysis of behavior (Part 1, pp. 301-350). Amsterdam: Elsevier. 
Maki, W. S., Moe, J. C., \& Bierly, C. M. (1977). Short-term memory for stimuli, responses, and reinforcers. Journal of Experimental Psychology: Animal Behavior Processes, 3, 156177.

McIlvane, W. J., \& Dube, W. V. (2000). Behavioral momentum and multiple stimulus control topographies. Behavioral and Brain Sciences, 23, 109.

McLaughlin, D. M., \& Carr, E. G. (2005). Quality of rapport as a setting event for problem behavior: Assessment and intervention. Journal of Positive Behavior Interventions, 7, 6891.

Nevin, J. A. (1974). Response strength in multiple schedules. Journal of the Experimental Analysis of Behavior, 21, 389-408.

Nevin, J. A. (1979). Reinforcement schedules and response strength. In M. D. Zeiler \& P. Harzem (Eds.), Advances in analysis of behaviour: Vol. 1. Reinforcement and the organization of behaviour (pp.117-158). Chichester, England: Wiley.

Nevin, J. A. (1984). Pavlovian determiners of behavioral momentum. Animal Learning \& Behavior, 12, 363-370.

Nevin, J. A. (1992). An integrative model for the study of behavioral momentum. Journal of the Experimental Analysis of Behavior, 57, 301-316.

Nevin, J. A., \& Grace, R. C. (2000). Behavioral momentum and the law of effect. Behavioral and Brain Sciences, 23, 73-130.

Nevin, J. A., \& Grosch, J. (1990). Effects of signaled reinforcer magnitude on delayed matchingto-sample performance. Journal of Experimental Psychology: Animal Behavior Processes, 16, 298-305. 
Nevin, J. A., Milo, J., Odum, A. L., \& Shahan, T. A. (2003). Accuracy of discrimination, rate of responding, and resistance to change. Journal of the Experimental Analysis of Behavior, $79,307-321$.

Nevin, J. A., Shahan, T. A., \& Odum, A. L. (2008). Contrast effects in response rate and accuracy of delayed matching to sample. The Quarterly Journal of Experimental Psychology, 61, 1400-1409.

Nevin, J. A., Tota, M. E., Torquato, R. D., \& Shull, R. L. (1990). Alternative reinforcement increases resistance to change: Pavlovian or operant contingencies? Journal of the Experimental Analysis of Behavior, 53, 359-379.

Nevin, J. A., Ward, R. D., Jimenez-Gomez, C., Odum, A. L., \& Shahan, T. A. (2009). Differential outcomes enhance accuracy of delayed matching to sample but not resistance to change. Journal of Experimental Psychology: Animal Behavior Processes, 35, 74-91.

O'Daly, M., Meyer, S., \& Fantino, E. (2005). Value of conditioned reinforcers as a function of temporal context. Learning and Motivation, 36, 42-59.

Odum, A. L., Shahan, T. A, \& Nevin, J. A. (2005). Resistance to change of forgetting functions and response rates. Journal of the Experimental Analysis of Behavior, 84, 65-75.

Perone, M., \& Courtney, K. (1992). Fixed-ratio pausing: Joint effects of past reinforcer magnitude and stimuli correlated with upcoming magnitude. Journal of the Experimental Analysis of Behavior, 57, 33-46.

Rilling, M. (1977). Stimulus control and inhibitory processes. In W. K. Honig \& J. E. R. Staddon (Eds.), Handbook of operant behavior (pp. 432-480). Englewood Cliffs, NJ: Prentice Hall. 
Reynolds, G. S. (1961). Behavioral contrast. Journal of the Experimental Analysis of Behavior, 4, 57-71.

Roberts, W. A., \& Kraemer, P. J. (1982). Some observations of the effects of intertrial interval and delay on delayed matching to sample in pigeons. Journal of Experimental Psychology: Animal Behavior Processes, 8, 342-353.

Santi, A. (1984). The trial spacing effect in delayed matching-to-sample by pigeons is dependent upon the illumination condition during the intertrial interval. Canadian Journal of Psychology, 38, 154-165.

Saunders, K. J., \& Williams, D. C. (1998). Stimulus-control procedures. In K. A. Lattal \& M. Perone (Eds.), Handbook of research methods in human operant behavior (pp. 193-228). New York: Plenum.

Schaal, D. W., Odum, A. L., \& Shahan, T. A. (2000). Pigeons may not remember the stimuli that reinforced their recent behavior. Journal of the Experimental Analysis of Behavior, 73, $125-139$.

Schuster, R. H. (1969). A functional analysis of conditioned reinforcement. In D. P. Hendry (Ed.), Conditioned reinforcement (pp. 192-235). Homewood, IL: The Dorsey Press.

Shettleworth, S., \& Nevin, J. A. (1965). Relative rate of response and relative magnitude of reinforcement in multiple schedules. Journal of the Experimental Analysis of Behavior, 8, 199-202.

Shahan, T. A., \& Jimenez-Gomez, C. (2006). Effects of self-administered alcohol concentration on the frequency and persistence of rats' attending to alcohol cues. Behavioral Pharmacology, 17, 201-211. 
Shahan, T. A., \& Podlesnik, C. A. (2005). Rate of conditioned reinforcement affects observing rate but not resistance to change. Journal of the Experimental Analysis of Behavior, 84, $1-17$.

Shahan, T. A., \& Podlesnik, C. A. (2008). Conditioned reinforcement value and resistance to change. Journal of the Experimental Analysis of Behavior, 89, 263-298.

Sidman, M. (1986). Functional analysis of emergent verbal classes. In T. Thompson \& M. D. Zeiler (Eds.), Analysis and integration of behavioral units (pp. 213-245). Hillsdale, NJ: Erlbaum.

Sidman, M. (1988). Tactics of scientific research: Evaluating experimental data in psychology. Boston: Authors Cooperative (Original work published 1960).

Skinner, B. F. (1966). The behavior of organisms: An experimental analysis. New York: Appleton-Century-Crofts (Original work published 1938).

Skinner, B. F. (1969). Contingencies of reinforcement. Englewood Cliffs, NJ: Prentice Hall. Spetch, M. L. (1985). The effect of intertrial interval food presentation on pigeons' delayed matching to sample accuracy. Behavioural Processes, 11, 309-315.

Stubbs, D. A., \& Pliskoff, S. S. (1969). Concurrent responding with fixed relative rate of reinforcement. Journal of the Experimental Analysis of Behavior, 12, 887-895.

Terrace, H. S. (1963). Discrimination learning with and without "errors". Journal of the Experimental Analysis of Behavior, 6, 1-27.

Terrace, H. S. (1966). Stimulus control. In W. K. Honig (Ed.), Operant behavior: Areas of research and application (pp. 271-344). New York: Appleton-Century-Crofts.

Weatherly, J. N., Melville, C. L., \& Swindell, S. (1997). Behavioral contrast with changes in duration and rate of reinforcement. Behavioural Processes, 40, 61-73. 
White, K. G. (1985). Characteristics of forgetting functions in delayed matching to sample. Journal of the Experimental Analysis of Behavior, 44, 15-34.

Wilkie, D. M. (1973). Behavioral interactions and stimulus control during conditional discriminations. Journal of the Experimental Analysis of Behavior, 20, 483-487.

Wilkie, D. M. (1984). Pigeons' spatial memory: IV. Effects of intertrial manipulations on delayed matching of key location. Canadian Journal of Psychology, 38, 178-195.

Williams, B. A. (1983). Another look at contrast in multiple schedules. Journal of the Experimental Analysis of Behavior, 39, 345-384.

Williams, B. A. (1984). Stimulus control and associative learning. Journal of the Experimental Analysis of Behavior, 42, 469-483.

Williams, B. A. (1994). Conditioned reinforcement: Experimental and theoretical issues. The Behavior Analyst, 17, 261-285.

Williams, B. A. (2002). Behavioral contrast redux. Animal Learning \& Behavior, 30, 1-20.

Wixted, J. T. (1989). Nonhuman short-term memory: A quantitative reanalysis of selected findings. Journal of the Experimental Analysis of Behavior, 52, 409-426.

Yerkes, R. M., \& Petrunkevitch, A. (1925). Studies of chimpanzee vision by Ladygin-Kohts. Journal of Comparative Psychology, 5, 99-108.

Zimmerman, E. H., Zimmerman, J., \& Russell, C. D. (1969). Differential effects of token reinforcement on instruction-following behavior in retarded students instructed as a group. Journal of Applied Behavior Analysis, 2, 101-112.

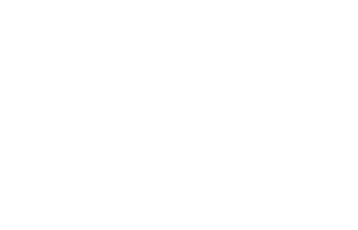

